\title{
Resultados electorales y el contexto socioeconómico: un análisis de las elecciones seccionales en el Ecuador 2009-2014
}

\section{Electoral Results and its Socioeconomic Context: An Analysis of Ecuador's 2009-2014 Subnational Elections}

\author{
José Gabriel Castillo y Francisca Granda
}

Recepción: 15 de julio de 2014

Aceptación: 30 de agosto de 2014

\section{Resumen}

Mediante el uso de datos de panel de las elecciones seccionales del 2009 y del 2014 e información censal del 2001 y 2010-2011, este estudio indaga sobre qué factores socioeconómicos influyeron en los resultados electorales a nivel de cantón: participación electoral, determinación del voto y cambios de tendencia a nivel cantonal. Encontramos evidencia que sugiere que las tasas de asistencia educativas a nivel cantonal son un factor determinante en el comportamiento electoral; que grupos poblacionales como los indígenas y afro-ecuatorianos se distinguen en su comportamiento electoral, y que variables atribuibles a la gestión local como el nivel de alcantarillado influyen en la probabilidad de que un cantón reelija o no a su autoridad (alcalde) vigente.

Palabras claves: factores de contexto, comportamiento electoral, factores socioeconómicos, participación electoral, voto nulo, cambio de tendencia.

\begin{abstract}
A panel data analysis was conducted for local (cantonal) electoral results in 2009 and 2014 and census data of 2001 and 2010-2011. The study examines context socio-economic factors that influenced the electoral results at cantonal level: turnout, spoiled/null and blank vote, and turnaround related to the incumbent party. We find evidence that educational rates are a determining factor of electoral behavior. Ethnic minorities such as indigenous and Afro-Ecuadorian groups differentiate in their aggregated electoral behavior and the influence of variables related to local competences, such as the status of local sewage infrastructure, defines whether a canton reelects its incumbent mayor or not.
\end{abstract}

Keywords: contextual factors, electoral behavior, socioeconomic factors, electoral participation, turnout, spoiled ballot papers, turnaround. 


\section{Introducción $^{1}$}

U

na de las áreas más enigmáticas en la política electoral es la comprensión del mecanismo de decisión del voto. Es decir, qué señales capta el votante y cómo forma sus percepciones para decidir en las urnas. Gran parte de la literatura en el tema ha sido desarrollada en las democracias occidentales de Europa y Norteamérica, en donde la institucionalidad política si bien no es la misma entre estos países, se ha fundamentado en sistemas políticos relativamente estables y cuyos protagonistas siguen siendo los partidos políticos. En los países de menor desarrollo institucional, como los latinoamericanos, el estudio de los votantes es reducido. Poco se conoce sobre el caso ecuatoriano. El estudio del comportamiento electoral de los sectores marginales de Guayaquil realizado por Menéndez-Carrión (1986), continúa siendo el estudio más riguroso, sustentado con evidencia empírica. Frente a este escaso conocimiento sobre el comportamiento de los votantes en el Ecuador, este trabajo es un esfuerzo que contribuye al estudio político mediante la implementación de técnicas de análisis empírico que buscan superar limitaciones metodológicas, para comprender cómo factores de contexto socioeconómico ayudan a explicar los resultados electorales a nivel cantonal, en particular de las dos últimas elecciones seccionales en el Ecuador, del 2009 y 2014.

Cómo se comporta el votante es una tarea difícil de investigar. Más todavía en la actualidad en donde el acceso y difusión de la información ya no solamente se realiza a través de medios de comunicación masivos y televisión, sino a través del uso de nuevas herramientas tecnológicas y canales como las redes sociales, en donde se han generado cambios sustanciales en la educación, la agenda mediática y el campo de acción del

1 Agradecemos la colaboración del Instituto de la Democracia y de la Unidad de Información Socioambiental de la Universidad Andina Simón Bolívar por la entrega de la información. También extendemos un sincero agradecimiento a todos los quienes participaron anónimamente en las entrevistas realizadas para este artículo. Los criterios expresados aquí corresponden a los autores y no reflejan la visión de ninguna de las instituciones colaboradoras o de las que forman parte. 
gobierno se han expandido ampliamente, y existen nuevos actores en la contienda política (ver Barnes, 1997). Estos elementos complejizan el proceso de decisión de los votantes; más aún en contextos en donde existen prácticas clientelares y corporativistas, en donde se carece de partidos políticos ${ }^{2}$ estables, y en donde la institucionalidad política formal ha perdido representatividad dando paso a alternativas anti-sistema (ver Andrade, 2009; Pachano, 2006; Roberts, próximamente). En tal medida, la capacidad de los incipientes partidos políticos para orientar el voto y la capacidad de los políticos en ejercicio de cumplir con las expectativas de los votantes es modesta.

El comportamiento electoral está influido por el contexto social, económico, cultural, institucional y político. Asimismo, factores de carácter psicológico y personal intervienen en las decisiones de voto. Este documento recoge una aproximación empírica, empleando datos de panel, para explicar exclusivamente como intervienen los factores socioeconómicos, como parte de las motivaciones de contexto, a las que está expuesto el votante. El panel incluye información a nivel cantonal de las elecciones seccionales del 2009 y el 2014, así como información censal de los años 2001 y 2010-2011. Estimamos un modelo en diferencias (equivalente a un modelo de efectos fijos) a fin de eliminar el potencial sesgo de información no observada (variables omitidas), que es constante en el tiempo y que explica una parte de la heterogeneidad de los procesos electorales a nivel cantonal. Este análisis parte del supuesto de que la dinámica electoral de un tiempo determinado $(t)$ responde de alguna forma a la situación socioeconómica previa (rezagada). Así aprovechamos la riqueza y representatividad de la información censal a nivel cantonal, lo que nos permite extender la interpretación del voto como una forma de retribución o castigo.

Varios resultados dan cuenta de la importancia de los factores socioeconómicos en el comportamiento electoral. Por un lado identifica-

2 Los partidos políticos, instituciones cuya función es agregar los intereses particulares para gobernar en aras del interés general e instituciones que se constituyen en los medios de expresión y canalización de las exigencias de los gobernados (Sartori, 1999: 54, 57). 
mos una importante relación positiva entre los niveles de educación a nivel cantonal (tasas netas de asistencia) y los niveles de participación electoral y determinación del voto (voto nulo vs. voto indeterminado). La presencia de población indígena y afro ecuatoriana a nivel cantonal interviene en la variabilidad de los resultados. Variables de aseguramiento, infraestructura y salud, tienen una limitada capacidad explicativa, y su interpretación requiere de un criterio de cautela. Asimismo, la influencia de estos factores se extiende hacia la identificación de cambios de tendencia política respecto del partido titular (incumbent). Aquí es interesante observar como variables de infraestructura, unas atribuibles a la gestión municipal versus otras fuera de sus competencias locales, evidencian patrones de comportamiento específicos e intervienen tanto en la posibilidad de reelección, como en la identificación del éxito electoral del partido de gobierno solo versus con alianzas.

Un porcentaje significativo de los resultados electorales puede ser explicado con base a la información recopilada para este estudio, sin embargo, queda un largo camino por recorrer que permita reconciliar las motivaciones intrínsecas, personales del votante, de las motivaciones de contexto. Este constituye un primer esfuerzo en una agenda amplia de investigación.

La primera sección del artículo presenta una revisión de la literatura relevante, tanto en la academia norteamericana y europea, como de los estudios relativos al Ecuador que fundamentalmente se concentran en el análisis del fenómeno del populismo. Consecutivamente, presentamos una breve reseña del contexto político electoral del país, enfocándonos en las elecciones seccionales del 2009 y el 2014. La tercera sección presenta la aproximación empírica utilizada para el análisis de los resultados electorales y resume el método, las variables y los supuestos que forman la parte central del estudio. La cuarta sección recoge la interpretación de los resultados, y presenta un debate sobre los límites de la interpretación. Finalmente, la quinta sección concluye el documento. 


\section{Revisión de la literatura}

La compresión de la toma de decisiones del votante por una u otra propuesta política o candidato en específico, ha sido abordada principalmente desde tres corrientes de pensamiento: el enfoque sociológico, el sicológico y el economicista, más conocido como de decisión racional (rational choice).

La sociología se centra en el estudio del desarrollo de los sistemas de partidos, en donde por un lado se analiza la secuencia histórica de los conflictos políticos y por otro lado los clivajes ${ }^{3}$ sociales. En esta corriente se destaca el estudio de Lipset y Rokkan (1967) que analizan los sistemas de partidos y alineamientos de los votantes basados en la posición que tienen con respecto a la clase social, la religión, la etnia, la nacionalidad, la región y el lugar de residencia urbano o rural. La crítica a este enfoque es que puede explicar la continuidad y la estabilidad del sistema político, pero tiene muy poco poder explicativo sobre los cambios electorales. Por ejemplo, es muy poco lo que la pertenencia a una clase social puede guiar al votante en aspectos que no están relacionados con su condición de clase. Esto no quiere decir que los votantes identifiquen a los partidos políticos de acuerdo a la clase social que representan, sino que estas señales tienen cada vez menos relevancia en la toma de decisiones del votante (Dalton and Wattenberg, 1993: 201).

La evidencia empírica en Europa y EEUU muestra que las diferencias en el voto de acuerdo a la clase social son cada vez menores, por lo que hoy en día se debate el escaso poder explicativo del enfoque sociológico. Ahora bien esta evidencia es paradójica cuando la pertenencia a una clase social tiene un efecto claro y directo respecto de las oportunidades sociales, por ejemplo en la posibilidad de acceder a educación universitaria, a un empleo en el futuro o a un determinado estilo de vida, aspectos que sí muestran una relación con la decisión de voto. Esto ha llevado a re-conceptualizar categorías, como la "clase social" y a

3 Anglicismo en las ciencias políticas que se deriva del inglés "cleavage" y que quiere decir segmentación, disociación o fractura. 
estudiar a los votantes con base a estos nuevos enfoques (Dalton y Wattenberg, 1993:199). Por otro lado, esto nos lleva a pensar lo siguiente: si bien los clivajes sociales anteriores se han ido desvaneciendo, nuevos clivajes se pueden suscitar en la orientación del voto. Eventualmente esto puede llevar a un nuevo realineamiento partidista o a la creación de nuevos partidos, de modo que nuevas divisiones sociales estructuren el voto (Dalton y Wattenberg, 1993: 201). La pertinencia del estudio de clivajes sociales en el Ecuador, y de serlo, cuáles son los clivajes sociales que influyen en el voto, es una tarea pendiente de la disciplina.

Frente a la debilidad de las explicaciones sociológicas sobre la decisión del voto, la investigación dio un giro hacia la psicología. Este enfoque busca analizar el proceso psicológico (cognitivo) que existe detrás de la decisión del voto. El comportamiento del votante parte de analizar comúnmente dos clases de eventos, uno es la decisión de votar o no (la participación electoral), y otro es por cuál candidato/s se vota. Una diversidad de factores convergen en la decisión del voto, de modo que no existe una única teoría que pueda explicar y responder estas dos preguntas. El enfoque psicológico busca comprender la respuesta individual en una elección al explicar las actitudes que influyen en el voto, es decir, la manera en que el individuo percibe los objetos y los eventos en el mundo político. Para ello intervienen condiciones externas y personales, unas son políticas, otras no, pero que pueden traducirse en motivaciones políticas en determinado momento. Así, lo que se busca es rastrear es qué condiciones personales y externas, que se han devenido en políticas, explican la decisión de voto.

La manera en que un evento no político se transforma en político, o un evento externo se vuelve personal, corresponde a procesos cognitivos y a percepciones que se desarrollan en el tiempo. Ahora bien, en el momento del voto, elementos personales y políticos son los que priman. El proceso por el cual un evento externo se vuelve personal es altamente influido por la comunicación, particularmente la presencia de los medios masivos donde se destaca la televisión y la comunicación interpersonal hoy exacerbada por las redes sociales. Al ser este un en- 
foque actitudinal, su análisis se restringe a las condiciones relevantes que ya son personales, de modo que aquellas condiciones que rigen a la comunicación y que intervienen en la transición de eventos externos a personales se quedan fuera de este enfoque. Es así que preguntas sobre cómo interviene la comunicación en la decisión del voto corresponde a una área de estudio aparte y complementaria a las teorías de comportamiento electoral (ver Campbell et. al, 1960: 18-37).

El enfoque psicológico argumenta que el ser partidario de una u otra corriente es más que un reflejo de la actual posición de clase del votante. Recurrir a factores demográficos bien puede proveer de una amplia información, pero su capacidad explicativa es limitada. La fortaleza del enfoque psicológico es que describe cómo todo individuo cuenta con la capacidad de juzgar sobre una gran parte de los fenómenos políticos. Así, esta corriente sostiene que la identificación con un partido político actúa como un filtro de las visiones del mundo político, lo que le orienta al votante no solo en decidir su voto (por la organización o persona de la que es partidaria), sino que le brinda la capacidad de interpretar temas de corto plazo o sobre determinados candidatos. En este enfoque además se identifican variables que tienen una relación directa con la decisión del voto como pueden ser: la actitud política, la presión de grupo, la comparación social, características de la personalidad del votante, la historia política familiar, la influencia de la familia, actitudes del candidato hacia ciertos temas, la depresión económica, temas de política local, identificación partidista, sentido del deber, nivel de integración al entorno social y percepción de la eficacia institucional, entre otras (Campbell et. al, 1960: 23; Leighley y Nagler, 1992).

Finalmente, el tercer enfoque es el enfoque económico que surge como una alternativa que escarba en las motivaciones sobre todo de corto plazo. Así este enfoque asume que el votante, como un agente racional, evalúa la "utilidad" de ejercer su derecho al voto, por medio de un análisis costo/beneficio y utiliza la información que tiene a su alcance para su decisión, considerando los costos involucrados en el proceso. Es decir, un individuo vota por el partido o candidato que él considera 
le dará más beneficio (neto) que cualquier otro (Downs, 1957: 137). En esta línea se asume que el votante desarrolla formas "simplificadas" de evaluación que utilicen factores actitudinales para reducir los costos de adquisición y procesamiento de la información. Por ejemplo, el individuo puede evaluar el desempeño en el pasado o las promesas de futuro, o puede orientarse por las tendencias de izquierda o derecha, lo que le reduce costos de información para decidir el voto (ver Dalton y Wattenberg, 1993: 198, 206-207).

Una de las hipótesis centrales del enfoque económico es la de "voto retrospectivo" (retrospective voting, Persson y Tabellini, 2000) que no es sino una forma de castigo/recompensa del votante en donde la probabilidad de ser reelegido depende del estado general de la economía. En otras palabras, un individuo vota por el candidato titular (incumbent), es decir, lo reelige, si los resultados económicos (macro o micro) son favorables, caso contrario vota en contra (Lewis-Beck et al., 2000: 183). Esta línea de investigación busca captar el nivel de significancia de variables económicas como el PIB, el desempleo, la inflación, etc. en la determinación del voto. Esta aproximación cuenta con un importante sustento empírico. En los estudios de los EEUU se observa este fenómeno, el votante norteamericano emite su voto considerando el desempeño de la economía en su conjunto más que su situación económica personal (Lewis-Beck et. al, 2000: 200). De manera complementaria el enfoque económico en combinación con el enfoque psicológico, también identifica otras motivaciones individuales como determinantes de los resultados electorales. Por ejemplo, en estudios sobre el abstencionismo y la participación electoral, el factor identificado como el más relevante es el factor educativo (ver Wolfinger, R. y Rosentone, 1980), mientras otros factores que actúan positivamente son la movilidad del individuo (geográfica), ingresos y condiciones de bienestar, la edad del elector, el estado civil y el tipo de ocupación.

En Latinoamérica, en un estudio de 21 elecciones presidenciales en 12 países, se observa que los candidatos en el poder pagan el precio por un mal desempeño económico así se trate de reveses de corto plazo (Remmer, 
1991: 785 en Lewis-Beck et. al, 2000 210). Pacek y Radcliff (1995: 735, en Lewis-Beck et. al, 2000: 210) en un estudio que recoge 52 elecciones en países de desarrollo medio, muestran como reducciones en el PIB afectan al candidato en el poder. Los autores, concluyen que las condiciones económicas son, por mucho, determinantes más importantes del voto en países en desarrollo que en los países europeos o EEUU. Finalmente, un análisis de las elecciones entre 1994 y 1998 en 38 países, desarrollados y en desarrollo, encuentra que, indistintamente de si el sistema de partidos es fragmentado o no, o las coaliciones de gobierno son fuertes o divididas, los votantes sí trasladan sus demandas económicas al voto (Wilkin et. al. 1997: 314 en Lewis-Beck et. al, 2000: 211). Sin duda estos resultados ponen sobre el tapete la importancia que tiene el desempeño económico para las elecciones, sobre todo las elecciones de carácter nacional.

El debate teórico entre estas tres corrientes persiste y los enfoques solamente pueden entenderse como interdependientes y no antagónicos, con atributos y debilidades, que deben ser preservados en un marco teórico más amplio sobre el comportamiento electoral (ver Campbell et. al, 1960). Conocer si los votantes están más predispuestos a votar de acuerdo factores de corto o largo plazo, en función de sus predisposiciones psicológicas y/o votan al evaluar desempeño económico del gobierno titular (incumbent), son preguntas vigentes. No existe una respuesta única y esta varía de acuerdo al contexto y al tiempo. Esta literatura nos invita a reflexionar sobre las distintas teorías y sus métodos para el análisis del comportamiento del votante. A continuación presentamos qué se conoce al respecto en el Ecuador.

\section{Literatura del Ecuador}

El estudio del comportamiento electoral en el Ecuador es un área en la política con escaso estudio académico. Las investigaciones se han centrado más en análisis institucionales sobre el sistema de partidos (Sánchez, 2008; Mejía, 1998; Conaghan, 1994), la orientación ideológica de los partidos (Freidenberg, 2000), la organización interna de los parti- 
dos (Alcántara y Freidenberg, 2001), la representación política (Barrera, 2001; Bustamante, 2000; Pachano, 2006) o análisis más comprensivos sobre la economía política y los partidos (Andrade, 2009; Roberts, próximamente). En general, al sistema político latinoamericano se lo caracteriza en permanente cambio, en donde las instituciones en si mismas se encuentran en tal estado de fluidez, que carecen de la posibilidad de definir y hacer cumplir las reglas del juego político (Weyland, 2002). Sobre el sistema de partidos ecuatoriano, a éste se lo ha caracterizado como fluido o débilmente institucionalizado. Es decir, los patrones de competencia son menos regulares, los partidos políticos no están enraizados en la sociedad, y existen organizaciones políticas débiles comúnmente dominadas por líderes p ersonalistas (Mainwaring y Torcal, 2006: 207, ver Conaghan 1995; Pachano, 2005; Roberts, próximamente).

Con respecto a los votantes, en cierta medida, los estudios con los que se cuenta corresponden a la investigación sobre el populismo en el país. Si bien la comprensión de esta categoría política va más allá del área de estudio de este artículo, es pertinente sugerir esta literatura en la medida en que da cuenta del entorno político en el que se vota en el Ecuador.

El populismo ha sido extensamente estudiado, aún con poco consenso sobre su significado y con poco respaldo de estudios empíricos; sin embargo, al preocuparse por comprender quién es "el pueblo," "la masa," "el otro," simultáneamente se explora el comportamiento de los votantes. Este estilo político iniciado en el Ecuador con el Velasquismo (1933-1972), se extendió a partir de la crisis del cacao de los treinta en donde partidos como la Concentración de Fuerzas Populares (CFP, fundado a fines de los cuarenta) y el Partido Roldosista Ecuatoriano (PRE, fundado en 1983), han sido los caracterizados como populistas. Políticos contemporáneos que se los asocia con este estilo, son Abdalá Bucaram (1996), Lucio Gutiérrez (protagonista del golpe de estado en enero del 2000 y luego Presidente en el 2002), y Rafael Correa (desde enero del 2006) (de la Torre, 2009; de la Torre, 2013).

El populismo se basa en un discurso polarizador que manifiesta la lucha entre el pueblo y la oligarquía, aludiendo a un enfrentamiento moral 
y ético entre el bien y el mal. Es una forma de relacionarse entre el líder y la masa. Un líder redentor, un ser carismático (ver Weber, 1994: 225230), que se opone a los enemigos quienes representan los males de la masa o "pueblo". Frente a la ambigüedad de estas categorías, los estudios populistas buscan estudiar quiénes están incluidos en ellas. Por ejemplo, la conocida expresión “iquerida chusma!” de Velasco Ibarra, se refería a la categoría "pueblo" como las clases bajas, honestas y mestizas. O cuando el CFP quería hacer una distinción entre el pueblo y la oligarquía, "el pueblo" son los pobres que se diferencian de los ricos en términos socioeconómicos, culturales, políticos y de estilos de vida. O cuando líderes del CFP buscaron referirse a dimensión étnica, la oposición es entre "la gente de la aristocracia" y los "cholos" (de la Torre, 2009: 199).

Los primeros estudios del populismo, realizados en la década de los setenta, sugieren que el grupo social más expuesto a asumir este discurso, por la crisis de la época cacaotera, era el subproletariado, asentado en la marginalidad de las grandes ciudades, especialmente de la Costa (Cueva, 1970). El estudio de Amparo Menéndez-Carrión (1986) es el más riguroso en cuanto a comprender el voto de los pobladores de barrios urbano marginales de Guayaquil en los ańos cincuenta y sesenta.

Menéndez cuestiona la perspectiva analítica convencional (de Oswaldo Hurtado, El Poder Politico en el Ecuador) sobre el comportamiento electoral de los sectores marginados y contribuye al debate al estudiar la relación que tiene la precariedad estructural en la que habita el votante de sectores marginados con su voto a favor de líderes populistas. La autora critica perspectivas que asumen a estos pobladores como pasivos, emocionales e irracionales, y argumenta que su voto es racional. Sostiene que es la precariedad estructural la que lleva a que intereses personales se transformen en las bases de la organización política, esta condición es la que impide que primen vínculos horizontales como formas de organización y comportamiento político, y que la capacidad política "de respuesta" sea la que se defina en términos de soluciones inmediatas a las demandas (Menéndez-Carrión, 1986: 271-332). En este contexto es comprensible que se generen redes de reclutamiento electoral urbano verticales y de 
índole clientelar. Es así que toma importancia el concepto de clientelis$\mathrm{mo}^{4}$ y maquinaria política ${ }^{5}$ para interpretar el voto de los barrios marginados (Menéndez-Carrión, 1986: 93-96). Su propuesta fue innovadora al entender el comportamiento electoral como "una respuesta utilitaria a una situación concreta" y como "una manifestación de clientelismo en acción", es decir, el intercambio de votos por servicios. Para la autora es racional en la medida que el voto es una práctica que tiene una lógica medio-fin ${ }^{6}$ (Burbano de Lara, et. al, 1989: 47).

Ahora bien, este enfoque dificulta entender las prácticas políticas del populismo más allá del comportamiento electoral (en ese caso, del velasquismo o cefepismo), lo cual lo hacen enfoques que analizan la cultura y el discurso frente a el/los "pueblos" (Burbano de Lara, et. al, 1989: 47). El estudio del populismo se centra tanto en el análisis del líder como del "pueblo" o "masas" a las que se dirige. Por un lado, indaga en las palabras, las acciones y las estrategias de los líderes ${ }^{7}$ (Knight, en de la Torre: 2009, 201), pero también explora las propias expectativas de los seguidores, sus culturas y discursos que son igualmente importantes para entender el fenómeno del populismo.

La extensa historia de exclusión de la vida política en el Ecuador, va de la mano con la existencia de este fenómeno, desde el cual se cuestiona la democracia liberal. El populismo alude a incluir al excluido. El populismo

4 El clientelismo designa una forma de intercambio dual que se da (a) entre actores de poder y estatus desigual, es (b) eminentemente utilitario y basado en la reciprocidad, y (c) es paternalista, particularista y privado (Menéndez-Carrión, 1986: 94).

5 Máquina política: es un sistema clientelar institucionalizado cuya finalidad básica es la obtención y retención del poder político. Toda vez que una red informal de clientelazgo político se vuelve parte de una organización partidista relativamente coordinada y disciplinada, surge la máquina política. A nivel de la barriada como escenario político, la máquina política provee al morador el tipo de beneficios que un patrón individual ofrecería, a través del dirigente como agente político, a cambio de su voto... la máquina política facilita la "negociación de acuerdos"... (Menéndez-Carrión, 1986: 102).

6 El término racional tiene algunas interpretaciones. Para Downs el término es económico y es sinónimo de "eficiencia". Las otras definiciones de racional es el de la lógica (racional en tanto pertenece a proposiciones lógicas) y psicológicas (alude a calcular a actuar sin emociones) (Downs, 1957: 137). En Menéndez parece referirse a racional en tanto lógico.

7 En el Ecuador, es muy popular el uso del término "caudillo" para aquellos líderes que perduran por décadas. Blanksten lo define como hombres que se miran a sí mismos como indispensables, llamados a salvar el país, el líder que siente "un llamado interno," de "fuerte personalidad" (Burbano de Lara, et. al: 1989: 32-34). 
politiza y desnaturaliza las desigualdades sociales (Roberts, 2003 en de la Torre: 2012: 152). Desde ahí aparece como una crítica a la democracia liberal, que en quienes la defienden se observa una concepción de esta como "una empresa civilizadora que educará y modernizará a los de abajo" (de la Torre: 2009: 193). Los populistas critican esta visión y defienden una democracia en donde "el pueblo" expresa su voluntad ocupando espacios públicos de los que se sentía o estaba excluido. Sin embargo, es una inclusión "estética o litúrgica más que institucional" (de la Torre: 2009: 193). Álvarez Junco (1994) plantea que "el líder difunde los mitos y los símbolos que identifican al 'pueblo' como legítimo portador de los valores nacional-democráticos y convoca los ritos y festejos en los que el sujeto colectivo emergente ratifica con su presencia la nueva religión cívica." (Álvarez Junco, 1994: 25-26 en de la Torre: 2009: 194) Por ello, es usual que el líder busque una relación directa con sus seguidores, sin intermediación, lo cual en sistemas democráticos menos institucionalizados como el Ecuador, resultan en círculos viciosos de difícil salida.

El análisis de la democracia liberal y la democracia "inclusiva/participativa," y la tensión entre estas visiones, está fuera del objeto de ese estudio. Sin embargo, es pertinente definir este contexto sobre el que se debate el votante. ¿A qué aluden los candidatos en su discurso? ¿qué de lo que realiza el candidato en funciones percibe el votante? ¿cómo recibe los mensajes el votante? ¿qué prima finalmente en su decisión de voto?, son todas preguntas que forman parte de las intermediaciones que se deben considerar al analizar el comportamiento del votante; más aún en el marco de una democracia plebiscitaria vigente, en donde el votante no solamente ha debido elegir entre sus representantes, sino que su voto (directo) ha sido la forma de llevar adelante importantes cambios institucionales (Conaghan et. al., 2008).

\section{El contexto electoral en el Ecuador}

Bajo el proyecto de democracia liberal esbozado para la transición al período democrático en el Ecuador en 1979, distintas visiones de democra- 
cia se mantuvieron en discusión y llegaron a expresarse electoralmente. Los cuatro partidos relativamente exitosos a nivel electoral en el período de retorno a la democracia (1979-1997) fueron el PRE, el PSC en la Costa y la Izquierda Democrática (ID) y la Democracia Popular (DP) en la Sierra. Estos partidos captaron la presidencia desde 1978 a 1996, de manera intercalada y sin reelegirse. En este período de reconstrucción de la democracia y las instituciones del Estado, el proceso político se caracterizó por liderazgos caudillistas y una estructura partidista jerárquica y central que no logró captar de una forma inclusiva las demandas sociales regionales perdiendo representatividad paulatinamente, proceso que deviene en el aparecimiento en la escena pública de candidatos outsiders. ${ }^{8}$

Un hito histórico en el país fue el levantamiento indígena en 1990 el cual llegó a constituirse en el movimiento de unidad plurinacional Pachacutik (MUPP) en 1996. Participaron en las elecciones presidenciales con un primer candidato outsider, Freddy Ehlers. Sin embargo, ganó las elecciones Abdalá Bucaram (PRE), candidato de tendencia populista y cuya presencia representó una amenaza a la institucionalidad en construcción. Luego de la caída de los Presidentes Bucaram, Jamil Mahuad y Gutiérrez, el cuarto líder outsider que llega a la presidencia con éxito hasta el momento es el Presidente Rafael Correa (2006). La llegada del Presidente Correa y su movimiento Alianza País (MPAIS), representa un momento de recuperación de los espacios de gobernabilidad, en un proceso de "destrucción constructiva," no sin críticas importantes respecto de la desinstitucionalización del Estado, y en donde se debilita la estructura partidista vigente de los partidos tradicionales y entra en el juego político el partido de gobierno. El éxito electoral se ha mantenido de manera sucesiva en varias instancias captando la presidencia, la Asamblea Nacional y ganado sucesivos referéndums y consultas populares.

Posterior a la instauración de la Asamblea Nacional Constituyente, el primer proceso relevante para nuestro análisis son las elecciones del 26 de abril de 2009, en donde se eligieron además, del presidente/

8 Que aparecen en la contienda política por primera vez. 
vicepresidente y miembros de la asamblea (diputados), todas las autoridades seccionales: prefectos, alcaldes, concejales, consejeros y miembros de las juntas parroquiales. Este "borrón y cuenta nueva" legitimó mediante el proceso democrático el proyecto político en ciernes denominado "Revolución Ciudadana", e instauró la presencia de MPAIS como una fuerza política institucionalizada en tanto en el gobierno nacional como en los gobiernos provinciales y locales.

Empujados por el momentum, en las elecciones seccionales del mismo año el partido de gobierno captó 9 prefecturas, fundamentalmente de la sierra, y 72 alcaldías de los 221 cantones a nivel nacional, desplazando a los partidos tradicionales en sus propios bastiones electorales como el PSC que pasó de tener 58 alcaldes en el 2004 a solamente 9 en el 2009, algo similar con el partido Izquierda Democrática, el Partido Roldosista Ecuatoriano y la Democracia Popular-Unión Demócrata Cristiana (ver Tabla 1). Partidos como MUPP, mantuvieron su presencia en provincias de la sierra-centro (Cotopaxi y Tungurahua), la Amazonia y cantones en donde su trayectoria y cuadros políticos se venían formando desde hace más de una década. El PSP, del defenestrado presidente Lucio Gutiérrez, mantuvo su presencia en las provincias de la Amazonía y la sierra-centro captando 30 alcaldías y 3 prefecturas.

El 23 de febrero de 2014 se llevaron a cabo las elecciones a gobiernos seccionales en el país, separadas de las elecciones presidenciales, que se realizaron el 17 de febrero de 2013, un año antes. Uno de los resultados políticos más interesantes de las últimas elecciones es el relacionado al cambio de tendencia política. Por un lado, el movimiento oficialista o partido de gobierno MPAIS redujo relativamente su presencia frente al número total de autoridades seccionales (alcaldes y prefectos). Este efecto se vio amplificado por la pérdida de varias capitales provinciales que favorecieron su postura en el 2009; particularmente Quito y Cuenca, por su importancia electoral nacional. No está por demás sugerir lo atípico de las elecciones seccionales del año 2009, post Asamblea Nacional Constituyente. En ese año la expresión democrática confirmó su apoyo a MPAIS que captó la primera magistratura en una sola "vuelta" 
electoral con cerca del $52 \%$ de los electores, además de una mayoría parlamentaria sin precedentes, 59 de 124 asambleístas. ${ }^{9}$

En las elecciones presidenciales de 2013 el partido de Gobierno demostró nuevamente su fuerza captando la presidencia en una sola "vuelta," sumado a una mayoría parlamentaria, que conjuntamente con movimientos locales aliados constituye una fuerza casi monopólica en la Asamblea. Las elecciones seccionales, realizadas a ańo seguido, proponen un momento de reflexión sobre el proceso electoral en donde la dirección de las fuerzas políticas no respondió inercialmente a la fuerza de los procesos electorales previos. Evidentemente este fue un proceso distinto al elegirse únicamente dignidades seccionales y si bien el movimiento oficialista en el balance mantuvo fuerza política, a nivel provincial la perdió en la sierra-centro y sur. Asimismo, en las elecciones cantonales, perdió en la mayoría de las capitales provinciales y en la capital nacional; mientras que en otras ciudades se reafirmó la presencia de movimientos y liderazgos locales, no necesariamente de una tendencia política distinta, ${ }^{10}$ pero derrotando a los candidatos oficiales.

Tabla 1.

Elecciones seccionales y cambios de tendencia en el Ecuador

\begin{tabular}{c|c|c|c|c|c|c|c|c|c}
\hline \multirow{2}{*}{ Organización Política } & \multicolumn{3}{|c|}{ Alcaldes (N.) } & \multicolumn{3}{c|}{ Prefectos (N.) } & Totales (N.) & \multirow{2}{*}{ Var. \% } \\
\cline { 2 - 10 } & $\mathbf{2 0 0 4}$ & 2009 & 2014 & $\mathbf{2 0 0 4}$ & $\mathbf{2 0 0 9}$ & $\mathbf{2 0 1 4}$ & $\mathbf{2 0 0 9}$ & $\mathbf{2 0 1 4}$ & \\
\hline MPAIS & & 72 & 69 & & 9 & 10 & 81 & 79 & $-2,5 \%$ \\
\hline Avanza & & & 36 & & & 1 & 0 & 37 & $100,0 \%$ \\
\hline MUPP & 19 & 26 & 29 & 3 & 4 & 3 & 30 & 32 & $6,7 \%$ \\
\hline Creo & & & 22 & & & 1 & 0 & 23 & $100,0 \%$ \\
\hline Suma & & & 17 & & & 2 & 0 & 19 & $100,0 \%$ \\
\hline PSC & 58 & 9 & 11 & 4 & 0 & 1 & 9 & 12 & $33,3 \%$ \\
\hline PSP & 22 & 30 & 11 & 0 & 3 & 1 & 33 & 12 & $-63,6 \%$ \\
\hline MPD & 9 & 10 & 6 & 2 & 1 & 2 & 11 & 8 & $-27,3 \%$ \\
\hline
\end{tabular}

9103 asambleístas provinciales, 15 asambleístas nacionales y 6 asambleístas del Exterior.

10 Movimientos políticos nuevos como en el caso de Avanza, afirman su presencia en una línea muy cercana al partido de gobierno. 


\begin{tabular}{c|c|c|c|c|c|c|c|c|c}
\hline PRE & 25 & 8 & 4 & 2 & 0 & 0 & 8 & 4 & $-50,0 \%$ \\
\hline PRIAN & 18 & 1 & 2 & 1 & 0 & 0 & 1 & 2 & $100,0 \%$ \\
\hline Izquierda Democrática & 23 & 3 & 0 & 4 & 1 & 0 & 4 & 0 & $-100,0 \%$ \\
\hline DP-UDC & 21 & 1 & 0 & 3 & 0 & 0 & 1 & 0 & $-100,0 \%$ \\
\hline $\begin{array}{c}\text { Otros (Partidos Y Movi- } \\
\text { mientos Provinciales) }\end{array}$ & 17 & 61 & 14 & 3 & 5 & 2 & 66 & 16 & $-75,8 \%$ \\
\hline Total & 212 & 221 & 221 & 22 & 23 & 23 & 244 & 244 & \\
\hline
\end{tabular}

Fuente: Trujillo (2004); CNE.

Nota: Información de partidos incluye alianzas con otras organizaciones.

En este escenario político institucional, el primer resultado electoral de interés que analizaremos está relacionado a la participación de los electores (turnout). A pesar de que en el Ecuador la participación electoral es obligatoria, los niveles de ausentismo/abstencionismo ${ }^{11}$ y las manifestaciones de votos indeterminados (nulos, blancos) dan cuenta de un proceso de decisión que requiere de mayor análisis. La importancia de este fenómeno está relacionada a la legitimación del proceso democrático; niveles elevados de ausentismo cuestionan la legitimidad política, especialmente si este fenómeno representa una respuesta específica (ej. descontento institucional) o una posición política frente al sistema democrático. Este fenómeno carece de una interpretación única respecto de sus motivaciones y consecuencias. Democracias relativamente estables, como en los países europeos y Estados Unidos, mantienen niveles de abstencionismo elevados y la asistencia a las urnas no es obligatoria.

En el Ecuador, los niveles de abstencionismo [ausentismo=1-\% de participación] actualmente están alrededor del promedio latinoamericano dentro de los países con voto obligatorio, aunque históricamente han sido superiores (ver Gráfico 1). Países con voto voluntario, como Colombia, algunos países Centroamericanos y recientemente Chile (último proceso presidencial), tienen tasas de ausentismo que superan el $50 \%$ de la población votante. Las elecciones presidenciales del Ecuador del año 2002 supusieron un nivel de ausentismo de cerca del 36\%, las del año 2006 alrededor de 24\%. En las elecciones seccionales del año

11 En este texto empleamos ambos términos como sinónimos. 
2009 el nivel de ausentismo alcanzó un 24\%, inclusive considerando que estas elecciones se realizaron conjuntamente con las presidenciales, lo que debió suponer un mayor nivel de movilización política. En las elecciones presidenciales del año 2013 (sin seccionales) mejoraron considerablemente los niveles de participación; se observó un nivel de ausentismo de solamente el 18,2\%.

No hay un patrón histórico determinado de participación electoral, más aún cuando el nivel de ausentismo solo se registra adecuadamente desde las elecciones de 1978-1979, cuando el voto se constituyó en un derecho universal ${ }^{12}$; sin embargo, si se considera la participación electoral desde el establecimiento de los padrones electorales (ver Gráfico 1), los niveles observados se han ido reduciendo. Por otro lado, el organismo electoral implementó en los últimos procesos electorales algunos programas para incentivar el voto y que van desde la inclusión de personas con discapacidad, hasta el voto asistido y "voto en casa" en doce provincias del país (CNE), enviando juntas receptoras móviles.

En el ańo 2014, tomando en cuenta la presencia de estos procesos, los niveles de ausentismo disminuyeron considerablemente a aproximadamente $17 \%$. Otro cambio importante se relaciona a la población electoral de referencia que también se ha modificado en estos años. Entre las reformas electorales más relevantes del Código de la Democracia aprobado en el ańo 2011 se aprobó el voto facultativo para las fuerzas armadas y policía en servicio activo y adicionalmente para ecuatorianos en el exterior, jóvenes entre 16 y 17 ańos y adultos mayores a 65 años ${ }^{13}$. Si analiza-

12 Hasta entonces el derecho al voto estuvo restringido por una serie de requisitos que fueron eliminándose progresivamente. En 1861 se suprime el requisito de propiedad, 1884 el requisito de capital para ser candidato. En 1897 se modifica la edad de 21 a 18 años. En 1928 se inaugura el voto femenino en Ecuador y América Latina (Matilde Hidalgo de Prócel). En 1945 se establece la obligatoriedad del voto para los alfabetizados. 1947 se crea la ley de partidos y se establecen padrones electorales mediante el uso de la cédula. En 1978 se establece el voto universal, que incluye a analfabetos y por lo tanto a un importante número de votantes excluidos: población pobre, indígenas y afroecuatorianos, campesinos y población rural. En el 2008 se establece el voto facultativo para adolescentes entre 16 y 18 ańos, fuerza pública en servicio activo, entre otros. Ver Verdezoto, N (2014) "El derecho al voto cambió nueve veces en el período republicano.” El Comercio, edición en línea.

13 Código de la Democracia (2011), Art.11. 
mos los niveles de ausentismo a nivel cantonal, los márgenes también se han reducido considerablemente en los dos años de análisis (ver Tabla 2).

Tabla 2.

Estadísticas sumarias de la participación electoral a nivel cantonal, elecciones seccionales 2009-2014

\begin{tabular}{c|c|c|c|c|c|c}
\hline \multirow{2}{*}{ Variable Dependiente } & \multicolumn{3}{|c|}{2009} & \multicolumn{3}{c}{2014} \\
\cline { 2 - 7 } & $\begin{array}{c}\% \\
\text { Ausentismo }\end{array}$ & $\begin{array}{c}\% \\
\text { Voto } \\
\text { nulo }\end{array}$ & $\begin{array}{c}\% \\
\text { Voto } \\
\text { indefinido }\end{array}$ & $\begin{array}{c}\% \\
\text { Ausentismo }\end{array}$ & $\begin{array}{c}\% \\
\text { Voto } \\
\text { nulo }\end{array}$ & $\begin{array}{c}\% \\
\text { Voto } \\
\text { indefinido }\end{array}$ \\
\hline No. de cantones & 221 & 221 & 221 & 221 & 221 & 221 \\
\hline Media (no ponderada) & 23,75 & 7,94 & 15,48 & 16,62 & 7,37 & 11,44 \\
\hline Std. Dev. & 8,10 & 2,70 & 5,54 & 7,26 & 2,92 & 4,47 \\
\hline Min & 7,37 & 1,71 & 3,10 & 5,03 & 0,91 & 1,42 \\
\hline Max & 66,74 & 15,89 & 28,18 & 59,92 & 15,26 & 22,83 \\
\hline
\end{tabular}

Fuente: CNE-IDD

Elaboración: autores

Nota: Voto indefinido $=$ Votos Nulos + Votos Blancos

\section{Gráfico 1.}

Tasas de ausentismo electoral en América Latina, elecciones presidenciales

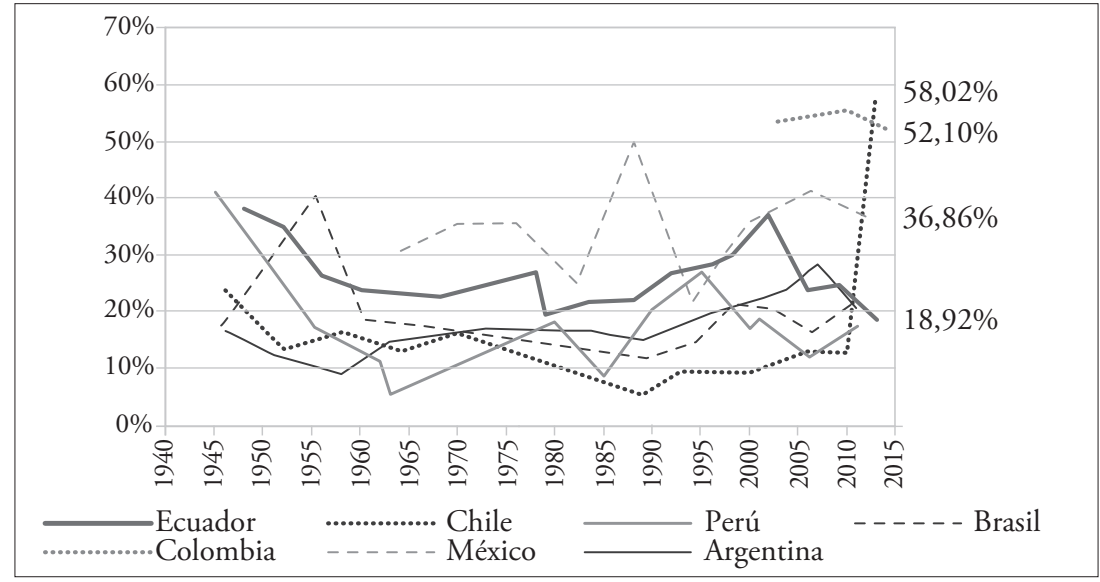

Fuente: International IDEA, online country data base Elaboración: autores 


\section{Aproximación empírica}

Identificar las preferencias del electorado y sus motivaciones para ejercer su derecho al voto constituye un reto desde el punto de vista empírico. Si consideramos el problema de decisión del votante como un problema de "elección racional" (Castillo et al. 2006), su decisión se deriva de un balance entre el beneficio percibido en el ejercicio del voto (o percepción de utilidad derivada de su compromiso político) y los costos relacionados al ejercicio del voto (ej. costos de movilización, penalización por no votar). De modo que, los resultados electorales agregados: asistencia a las urnas (turnout), votos nulos, votos blancos, apoyo a las instituciones, preferencias electorales, etc.; son finalmente el resultado de este proceso de decisión.

Sin perjuicio de otros enfoques, las motivaciones del elector provienen de dos fuentes principales: factores individuales, y factores de contexto. Los primeros son la respuesta a gustos y preferencias individuales formados por un proceso, consciente o inconsciente, de identificación frente a las alternativas de decisión; por ejemplo, factores demográficos como género y edad son con frecuencia atributos comunes de la estratificación electoral, y constituyen comúnmente recursos de focalización para estrategias políticas. Esfuerzos de cómo llegar a la juventud o cómo explotar la identificación de género apelan a estos factores. Otros factores individuales son hábitos electorales, ideología política, percepción individual de la institucionalidad democrática, identificación personal con el discurso, identificación personal con el candidato, etc. Analizar empíricamente estos factores requiere del uso de información a nivel individual no recolectada para este análisis. Si bien esto constituye una importante limitación, la importancia relativa de estos factores como determinantes de los resultados electorales no está clara en la literatura y la evidencia es divergente y condicional al contexto ${ }^{14}$. Independientemente de estas limitaciones, dejaremos explícitos los argumentos y la racionalidad de las conclusiones expuestas.

14 Ver Laghley et al. (1992), Patterson y Caldeira (1983). A nuestro conocimiento, no hay estudios empíricos que desarrollen este tema en el Ecuador. 
Por otro lado, los factores de contexto son el resultado de la interacción del individuo con su entorno, de la influencia que la dinámica colectiva, composición social, estructura institucional o realidad socio económica, y como estos factores influyen en las preferencias o cómo éstas afectan las percepciones individuales. Los factores de contexto son en sí mismos mucho más que la agregación de las condiciones individuales; el contexto absorbe los spill overs (desborde, difusión) de información fruto de los factores relacionados al capital social, la composición social, y la influencia de la red de interacción social sobre la que el individuo (votante) se desenvuelve (networks). Si bien en general los factores de contexto se reconocen claramente como importantes, su investigación es limitada tanto por limitaciones de disponibilidad de información como por la complejidad de la interacción de los fenómenos sociales.

La sección empírica de este estudio se concentra exclusivamente en analizar la influencia de las variables socioeconómicas a nivel cantonal, como parte de estos factores de contexto, de forma que sea posible identificar patrones que determinan algunos de los resultados electorales más relevantes de las elecciones seccionales a Alcalde en Ecuador, en los dos últimos períodos. Vale recalcar que, a priori, no existe razón para preferir los factores de contexto por sobre los individuales como determinantes de resultados electorales; en este estudio nos concentraremos en los de contexto aprovechando la disponibilidad de información electoral y censal reciente. En las secciones correspondientes exponemos nuestra interpretación de los resultados que fue complementada con entrevistas a profundidad realizadas a actores políticos y generadores de opinión clave en algunas localidades del país y abrimos de esta forma la discusión de estos resultados para una agenda de investigación más amplia.

\section{Datos}

Para el análisis aprovechamos la información de las últimas dos elecciones seccionales en el Ecuador, 26 de abril de 2009 y 23 de febrero de 2014, provista por el Instituto de la Democracia y el Consejo Nacional 
Electoral y que recopila los resultados a nivel cantonal de las elecciones a alcaldes. Dado que el objetivo es analizar si los factores de contexto socio económico pueden explicar parcialmente los resultados electorales agregados, es necesario abordar el problema tomando en cuenta los cambios en dichas condiciones y no únicamente los niveles de las variables socioeconómicas observados al momento de cada elección, que constituyen en sí el tablero preestablecido de cada proceso. La información censal disponible en el Ecuador ofrece la oportunidad de combinar estos factores atando cada proceso eleccionario a condiciones socioeconómicas específicas. Para el efecto se consolidó un panel de datos cantonal constituido por información del VI Censo de Población y V de Vivienda de 2001 y el VII Censo de Población y VI de Vivienda de 2010, levantados por el INEC ${ }^{15}$.

En total el análisis comprende la información de 212 cantones a nivel nacional. Se excluyeron las regiones geográficas no delimitadas: Las Golondrinas, Manga del Cura y El Piedrero. Adicionalmente, se excluyen del análisis cantones que fueron creados o delimitados recientemente y sobre los cuales no se dispone de información específica de referencia, bien sea en alguno de los censos o en las elecciones a analizar; este es el caso de: La Concordia, Santo Domingo, Santa Elena, La Libertad, Salinas, Camilo Ponce Enriquez, Quinsaloma, Paquisha y Tiwinza.

\section{Modelo}

El modelo econométrico planteado para el análisis empírico es un modelo simple de datos de panel que tiene la forma funcional tradicional:

$$
y_{i t}=X_{i t} \beta+\alpha_{i}+\mu_{i t}
$$

15 Agradecemos la entrega y el procesamiento de información de la Unidad de Información Socioambiental de la Universidad Andina Simón Bolívar. 
En donde $i$ es el subíndice de cantones del Ecuador, y $t=2009$, 2014, los dos períodos de análisis. La variable dependiente adoptará los valores de varios resultados electorales a analizar: ausentismo, votos nulos (como una decisión política definida), votación indefinida (blancos y nulos) y el cambio de tendencia (a favor o en contra) frente al movimiento oficialista o partido de gobierno. es una matriz compuesta de 32 de los indicadores socioeconómicos a nivel cantonal relevantes, resumidos en las siguientes categorías: tasas netas de educación, variables poblacionales, variables de salud y variables de infraestructura. corresponde a atributos particulares de cada unidad territorial (cantón) que no son observables (cuantificables) o que siéndolo, estos no cambian (significativamente) en el tiempo ${ }^{16}$, como por ejemplo factores culturales, tradiciones, etc. Omitir estos factores, es decir estimar un modelo simplificado (sin ), daría como resultado coeficientes de estimación sesgados e inconsistentes puesto que dichos atributos, particulares a cada cantón, pueden estar directamente correlacionados con las características socioeconómicas ${ }^{17}$. La estrategia de estimación por lo tanto responde a un modelo de "efectos fijos," es decir, un modelo que tome en cuenta esta correlación y la neutralice en la estimación ${ }^{18}$. Esto no quiere decir que factores

16 También se puede hablar de una tasa de cambio más lenta, y por lo tanto menos representativa, así por ejemplo, cambios en la composición generacional, en la composición de género, u otras estructuras particulares a cada cantón, estarían incluidas en .

17 Matemáticamente: . Este supuesto flexibiliza el supuesto de estimación implícito en los procedimientos de "efectos aleatorios" y su consideración en la estimación es lo que se conoce como estimación de "efectos fijos." Por ejemplo, si el nivel cultural (la cultura) de una localidad o sus tradiciones, ambos hasta cierto punto intangibles, inciden en que su población sea más proclive a educarse, entonces las tasas netas de asistencia están siendo afectadas por una característica no observada en el modelo (absorbida en el parámetro ). Ignorar este elemento en la estimación resultaría en estimadores sesgados e inconsistentes. Por eso la importancia de emplear un modelo de Efectos Fijos.

18 La estimación de Primeras Diferencias cuando se trata de un modelo con $\mathrm{t}=2$, es numéricamente igual a la estimación por Efectos Fijos (within) es decir con desviaciones respecto de las medias. Alternativamente se puede estimar el mismo modelo utilizando una variable dummy para cada unidad geográfica (Mínimos Cuadrados con Variables Dummy) que arrojaría coeficientes de estimación similares a costa de un modelo más intensivo computacionalmente. Las diferencias entre estos métodos están sobretodo relacionadas a la eficiencia. En condiciones de correlación serial, es decir cuando las observaciones se relacionan a sus propias observaciones en períodos previos, el modelo de Primeras Diferencias es más eficiente y por lo tanto el preferido en nuestra aproximación. El lector interesado puede revisar las referencias bibliográficas, en particular: Wooldridge (2010) y Cameron y Trivedi (2010). 
que a nivel agregado son fijos (de cambio despreciable) en el tiempo, ej. composición de género, no afectan las decisiones del voto; es posible que el género actúe como una motivación individual del votante y por lo tanto ayuden a explicar parte de su comportamiento; sin embargo, el modelo con las características planteadas únicamente se concentra en el comportamiento agregado a nivel cantonal y por lo tanto sus resultados deben ser interpretados únicamente en este contexto. Los resultados a desarrollar no constituyen evidencia del comportamiento individual, sino del comportamiento agregado, del comportamiento del cantón y por lo tanto el modelo explica como los indicadores socioeconómicos determinan el contexto electoral únicamente a nivel cantonal.

Una forma intuitiva de estimar este modelo, neutralizando la heterogeneidad no observada de cada cantón, es empleando un modelo en "primeras diferencias", es decir, un modelo que tome en cuenta las variaciones (no los niveles) en ambos períodos para todas las variables; nótese que de esta forma se elimina directamente los factores que no varían en el tiempo ( y la constante) y por lo tanto se elimina el sesgo generado por las características fijas en el tiempo. El modelo a estimar se transforma entonces de la siguiente forma:

$$
\begin{gathered}
\left(y_{i t}-y_{i, t-1}\right)=\left(X_{i t}-X_{i, t-1}\right) \beta+\left(\mu_{i t}-\mu_{i, t-1}\right) \\
\dot{y}_{i t}=\dot{X}_{i t} \beta+\dot{\mu}_{i t}
\end{gathered}
$$

Este modelo asume que la variación de los indicadores socioeconómicos observables es independiente de cualquier otro factor o características, observables o no, que no varían en el tiempo (time invariant). Un supuesto adicional, más de carácter técnico se relaciona a la "exogeneidad débil," es decir, en el modelo de "primeras diferencias" solamente se requiere que no esté correlacionado con . Tomando en cuenta que la información socioeconómica precede a la información electoral en el panel, este supuesto es suficiente para obtener estimaciones consisten- 
Resultados ELECTORALES Y EL CONTEXTO SOCiOECONÓMiCo:

UN ANÁLISIS DE LAS ELECCIONES SECCIONALES EN EL ECUADOR 2009-20I 4

tes. Finalmente el modelo puede ser estimado por Mínimos Cuadrados Ordinarios. ${ }^{19}$

También es importante notar que la información estadística empleada no corresponde en estricto sentido a los años de los procesos electorales, por obvias limitaciones instrumentales ${ }^{20}$; sin embargo, la información censal constituye la información disponible y más rica, con representatividad a nivel cantonal. Este análisis parte del supuesto de que la dinámica electoral de un proceso $(\mathrm{t})$ responde a la situación socioeconómica rezagada, de uno o varios períodos acumulados $(\mathrm{t}-\mathrm{j})$. Varios canales son posibles en este escenario. Por un lado, aplicable a las autoridades reelectas, la percepción de la gestión institucional en un período ( $\mathrm{t}$ ) se forma y expresa tanto en el mismo período como en períodos posteriores y, por lo tanto, el voto puede constituir una forma de retribución/castigo. De la misma forma, se mezclan otros factores en el proceso de decisión. Este documento no intenta identificar un canal específico, sencillamente busca poner en evidencia (con mayor rigurosidad cuantitativa) que factores socioeconómicos explican mejor los resultados electorales y abrir así el abanico de posibilidades de estudio.

Los coeficientes de estimación que se obtienen con base a este procedimiento y bajo los supuestos descritos (ver pies de página correspondientes) son consistentes e insesgados; sin embargo, ¿̨representan efectos causales? No existe razón alguna en este diseño para argumentar a favor o en contra de una relación causal; sin embargo, al no tratarse de un

19 Una de las limitaciones del uso de este procedimiento de estimación es que no se puede analizar el efecto de variables observables que no cambian en el tiempo, ej. la identificación de la región (Costa, Sierra u Oriente). Esta influencia se puede estimar por "efectos aleatorios" no obstante a costa de asumir que no existe correlación entre las variables omitidas, constantes en el tiempo y los regresores del modelo. A nuestro criterio este costo es mayor al beneficio de identificar estos efectos que no son centrales en el análisis, por lo que nos concentraremos únicamente en las variaciones de los indicadores socioeconómicos.

20 Los censos en el Ecuador tienen una periodicidad de 10 años aproximadamente. Se trabajan alternativas que empleen información socioeconómica mediante las encuestas del INEC disponibles, no obstante, la representatividad y precisión de un Censo es una ventaja que decidimos explotar en esta primera aproximación, asumiendo el costo de no contar con información específica de períodos homogéneos previos a los dos procesos electorales. Entre el censo del 2001 y las elecciones del 2009 hay 8 años de diferencia, mientras entre el censo del 2010-2011 y las elecciones de 2014 hay al menos 3 años. 
diseño experimental sugeriremos los resultados como correlaciones relevantes e informativas, no efectos directamente causales. Diferenciar la causalidad requiere de un análisis exhaustivo de las condiciones tanto de la información, por posibles problemas de errores de medición, como del diseño y los supuestos de identificación del modelo. El planteamiento del modelo supera algunos de los problemas básicos de endogeneidad, en particular minimiza el problema de variables omitidas; algunos de estos problemas los trataremos en la sección de resultados, no obstante, siguiendo a Angrist y Pischke (2009) “... es importante evitar afirmaciones excesivamente fuertes al interpretar estimaciones de efectos fijos (en cualquier caso, nunca una mala práctica para un econometrista)". Esta sección se concentra únicamente en analizar las variables de contexto en los resultados electorales agregados, por lo tanto mantendremos un criterio de cautela en las conclusiones del análisis cuantitativo.

\section{Resultados}

\section{Participación electoral y decisión del voto}

\section{Nivel de participación / ausentismo}

En el Ecuador, la evidencia sobre la influencia de los factores socioeconómicos en los resultados electorales a nivel cantonal es diversa. Por un lado, son pocos los indicadores que tienen un nivel de influencia significativo (ver Tablas 3 y 5). Los índices educativos son los de mayor relevancia, resultados consistentes con otros estudios realizados en sistemas electorales distintos (Laghley et al. 1992; Lewis-Beck and Stegmaier, 2000). En particular, la educación secundaria indígena, y la educación superior general y específica de la población afro ecuatoriana; todos factores estadísticamente significativos ( $\mathrm{p}$-value $<0,05$ ). En promedio, un incremento de $10 \%$ en la tasa neta de asistencia a la educación secundaria indígena incrementa el nivel de participación (reduce el nivel 
de ausentismo) en aproximadamente medio punto porcentual; al mismo tiempo, un cambio porcentual similar en la tasa neta de asistencia a educación superior incrementa el nivel de participación en 1,6\% (el efecto equivalente de la educación superior en la población afro ecuatoriana es de $1,2 \%$ ). La educación primaria y secundaria general no demuestra ser un elemento diferenciador respecto de los niveles de participación electoral a nivel cantonal.

En cuanto a los indicadores de población, estos demuestran algunas particularidades relevantes del proceso electoral ecuatoriano. La participación de organizaciones indígenas, campesinas y negras en las décadas del 80 y $90^{21}$, constituye uno de los procesos políticos etno-reivindicativos más significativos desde el punto de vista democrático en el Ecuador. La influencia de estas organizaciones en los procesos electorales seccionales ha sido evidente y a nivel local se ha consolidado un apoyo importante y estable, por ejemplo respecto de MUPP, en los dos últimos procesos electorales seccionales. En relación a la composición étnica, el único factor correlacionado con los niveles de ausentismo es el porcentaje de hogares afroecuatorianos; un 10\% de incremento en el porcentaje de hogares afro en un cantón involucra una reducción de 2,8\% ( $\mathrm{p}$-value $<0,05$ ) en el nivel de ausentismo (lo mismo sucede con los hogares indígenas, aunque su variación es mucho mayor y por lo tanto sus errores estimados, por lo que no constituye un elemento significativo en nuestra aproximación).

Los resultados en los indicadores de aseguramiento son de alguna forma ambiguos. Si bien por un lado en los últimos años los niveles de acceso a la seguridad social se han incrementado a partir de la puesta en vigencia de la Ley de Seguridad Social (2009) ${ }^{22}$, lo cual se ve reflejado en el desplazamiento positivo de la distribución en los datos censales ${ }^{23}$, los

21 En particular la conformación la CONFENIAE (1984), la CONAIE (1986), de la FENOCIN (1997) y creación del Movimiento de Unidad Plurinacional Pachakutik (1996).

22 La ley fue publicada en el Registro Oficial en mayo del 2009 y establece la obligatoriedad en el Seguro General Obligatorio, con criterios de universalidad, equidad y eficiencia.

23 Las medidas de locación: media, mediana, máximos y mínimos, se incrementan (la distribución se desplaza positivamente) para ambos indicadores de aseguramiento durante los años 2009 al 2014. 
efectos en cuanto a la participación electoral en el contexto difieren si se trata de la población general o la PEA-Población Económicamente Activa (un subset de la primera). En promedio, mayor acceso a seguridad social de la población general involucra mayor nivel de participación política, resultado que va alineado a los argumentos de participación democrática y las condiciones estructurales; sin embargo, si analizamos únicamente el subset de la población vinculada al mercado laboral (o en búsqueda de esta vinculación), el efecto es opuesto y supone mayor nivel de ausentismo conforme mayor número personas del cantón forman parte de la PEA. Los errores estimados para estos parámetros son amplios y por lo tanto no podemos esbozar ninguna conclusión definitiva al respecto (son parámetros no significativos); dejaremos explícitos los resultados para ampliar su análisis en investigaciones posteriores.

Tabla 3.

Resultados electorales e indicadores socio económicos

\begin{tabular}{c|c|c|c|c|c|c}
\hline \multirow{2}{*}{ Variable dependiente } & \multicolumn{2}{|c|}{$\%$ Ausentismo } & \multicolumn{2}{c|}{$\%$ Voto_nulo } & \multicolumn{2}{c}{$\%$ Voto_indefinido } \\
\cline { 2 - 7 } & $\beta$ & $\operatorname{se}(\beta)$ & $\beta$ & $\operatorname{se}(\beta)$ & $\beta$ & $\operatorname{se}(\beta)$ \\
\hline Educación & & & & & & \\
\hline $\begin{array}{c}\text { D.tasa neta de asisten- } \\
\text { cia primaria }\end{array}$ & 12,46 & $(18,09)$ & $-0,0442$ & $(0,0551)$ & $-0,113$ & $(0,0784)$ \\
\hline $\begin{array}{c}\text { D.tasa neta de asisten- } \\
\text { cia primaria, indígena }\end{array}$ & $-4,600$ & $(3,630)$ & 0,0106 & $(0,0122)$ & 0,000174 & $(0,0185)$ \\
\hline $\begin{array}{c}\text { D.tasa neta de asisten- } \\
\text { cia primaria, afro }\end{array}$ & $-1,492$ & $(4,326)$ & 0,000882 & $(0,0142)$ & 0,00479 & $(0,0394)$ \\
\hline $\begin{array}{c}\text { D.tasa neta de asisten- } \\
\text { cia secundaria }\end{array}$ & $-2,474$ & $(7,441)$ & $-0,0397$ & $(0,0386)$ & $-0,121^{*}$ & $(0,0651)$ \\
\hline $\begin{array}{c}\text { D.tasa neta de asisten- } \\
\text { cia secundaria, indígena }\end{array}$ & $-4,841^{* *}$ & $(2,379)$ & 0,00688 & $(0,00676)$ & 0,0151 & $(0,0136)$ \\
\hline $\begin{array}{c}\text { D.tasa neta de asisten- } \\
\text { cia secundaria, afro }\end{array}$ & $-1,697$ & $(2,200)$ & $-0,00397$ & $(0,00897)$ & $-0,00371$ & $(0,0276)$ \\
\hline $\begin{array}{c}\text { D.tasa neta de asisten- } \\
\text { cia superior }\end{array}$ & $-15,89^{*}$ & $(8,641)$ & $0,0993^{* *}$ & $(0,0434)$ & $-0,0730$ & $(0,106)$ \\
\hline $\begin{array}{c}\text { D.tasa neta de asisten- } \\
\text { cia superior, indígena }\end{array}$ & $-0,0442$ & $(4,183)$ & $-0,0000555$ & $(0,0212)$ & $-0,0293$ & $(0,0314)$ \\
\hline $\begin{array}{c}\text { D.tasa neta de asisten- } \\
\text { cia superior, afro }\end{array}$ & $-12,21^{* *}$ & $(5,703)$ & $-0,0415^{* *}$ & $(0,0204)$ & $-0,106^{*}$ & $(0,0640)$ \\
\hline
\end{tabular}


Resultados electorales y el CONTEXTO SOCiOeconómico:

UN ANÁLISIS DE LAS ELECCIONES SECCIONALES EN EL ECUADOR 2009-20I 4

\begin{tabular}{|c|c|c|c|c|c|c|}
\hline $\begin{array}{c}\text { D.tasa neta de alfabe- } \\
\text { tismo }\end{array}$ & $-9,971$ & $(28,83)$ & 0,126 & $(0,116)$ & $-0,425^{* *}$ & $(0,201)$ \\
\hline $\begin{array}{c}\text { D.tasa neta de alfabetis- } \\
\text { mo, indígena }\end{array}$ & $-2,646$ & $(4,165)$ & $-0,0262$ & $(0,0238)$ & $-0,0711$ & $(0,0439)$ \\
\hline $\begin{array}{l}\text { D.tasa neta de alfabetis- } \\
\text { mo, afro }\end{array}$ & 14,40 & $(9,581)$ & 0,0289 & $(0,0273)$ & 0,0306 & $(0,0680)$ \\
\hline \multicolumn{7}{|l|}{$\begin{array}{c}\text { Población y asegura- } \\
\text { miento }\end{array}$} \\
\hline $\begin{array}{l}\text { D.porcentaje de hoga- } \\
\text { res indígenas }\end{array}$ & $-9,495$ & $(7,943)$ & 0,00497 & $(0,0443)$ & $-0,0433$ & $(0,0779)$ \\
\hline $\begin{array}{l}\text { D.porcentaje de hoga- } \\
\text { res afro }\end{array}$ & $-28,04^{* *}$ & $(13,75)$ & 0,0990 & $(0,0764)$ & $-0,0674$ & $(0,141)$ \\
\hline D. consumo (USD) & $-0,111^{* *}$ & $(0,0426)$ & 0,0000323 & $(0,000279)$ & $-0,000389$ & $(0,000471)$ \\
\hline $\begin{array}{l}\text { D.porcentaje de indi- } \\
\text { gencia }\end{array}$ & $-3,485$ & $(4,673)$ & $-0,0420$ & $(0,0373)$ & $-0,0786$ & $(0,0518)$ \\
\hline $\begin{array}{c}\text { D.porcentaje de po- } \\
\text { breza }\end{array}$ & 3,083 & $(6,070)$ & 0,0689 & $(0,0447)$ & 0,0348 & $(0,0556)$ \\
\hline $\begin{array}{l}\text { D.porcentaje de po- } \\
\text { blación con seguridad } \\
\text { social }\end{array}$ & $-2,569$ & $(10,76)$ & $-0,0289$ & $(0,0596)$ & 0,0470 & $(0,124)$ \\
\hline $\begin{array}{l}\text { D.porcentaje de PEA } \\
\text { con seguridad social }\end{array}$ & 4,040 & $(5,767)$ & 0,0271 & $(0,0320)$ & $-0,0987$ & $(0,0902)$ \\
\hline \multicolumn{7}{|l|}{ Infraestructura } \\
\hline $\begin{array}{l}\text { D.porcentaje de vivien- } \\
\text { das con agua potable al } \\
\text { interior de la vivienda }\end{array}$ & 1,362 & $(3,905)$ & $-0,0119$ & $(0,0222)$ & 0,0490 & $(0,0393)$ \\
\hline $\begin{array}{c}\text { D.porcentaje de vivien- } \\
\text { das con acceso a la red } \\
\text { pública de alcantari- } \\
\text { llado }\end{array}$ & $10,80^{*}$ & $(6,209)$ & $-0,00432$ & $(0,0247)$ & $-0,0440$ & $(0,0574)$ \\
\hline $\begin{array}{c}\text { D.porcentaje de vi- } \\
\text { viendas de eliminación } \\
\text { de basuras con carro } \\
\text { recolector }\end{array}$ & $-2,438$ & $(3,121)$ & $-0,00530$ & $(0,0141)$ & 0,0457 & $(0,0300)$ \\
\hline $\begin{array}{l}\text { D.porcentaje de hoga- } \\
\text { res con electricidad }\end{array}$ & $-4,813$ & $(5,169)$ & $0,0381^{*}$ & $(0,0201)$ & $0,0838^{* * *}$ & $(0,0316)$ \\
\hline $\begin{array}{c}\text { D.porcentaje de vi- } \\
\text { viendas con paredes de } \\
\text { hormigón, ladrillo o } \\
\text { bloque }\end{array}$ & $-6,547$ & $(6,719)$ & $-0,0583^{* *}$ & $(0,0246)$ & 0,0727 & $(0,0593)$ \\
\hline
\end{tabular}




\begin{tabular}{|c|c|c|c|c|c|c|}
\hline $\begin{array}{c}\text { D.porcentaje de vivien- } \\
\text { das con piso entablado, } \\
\text { de parquet, baldosa, } \\
\text { vinyl, ladrillo o ce- } \\
\text { mento } \\
\end{array}$ & $-10,64^{*}$ & $(6,008)$ & 0,0266 & $(0,0223)$ & 0,0467 & $(0,0404)$ \\
\hline $\begin{array}{c}\text { D.porcentaje de hogares } \\
\text { con servicio higiénico } \\
\text { de uso exclusivo }\end{array}$ & $-2,653$ & $(5,653)$ & $-0,00222$ & $(0,0188)$ & $-0,0886^{* *}$ & $(0,0413)$ \\
\hline \multicolumn{7}{|l|}{ Salud } \\
\hline $\begin{array}{c}\text { D.porcentaje de vi- } \\
\text { viendas con hasta tres } \\
\text { personas por cuarto }\end{array}$ & 20,29 & $(14,39)$ & 0,0555 & $(0,0562)$ & 0,126 & $(0,0991)$ \\
\hline $\begin{array}{c}\text { D.personal de salud por } \\
10000 \text { personas }\end{array}$ & $0,0871^{*}$ & $(0,0496)$ & 0,000247 & $(0,000305)$ & 0,000939 & $(0,000574)$ \\
\hline $\begin{array}{c}\text { D.personal público de } \\
\text { salud por } 10000 \text { per- } \\
\text { sonas }\end{array}$ & 0,00680 & $(0,0740)$ & $-0,000207$ & $(0,000371)$ & $-0,00144^{*}$ & $(0,000849)$ \\
\hline $\begin{array}{l}\text { D.proporción de nińos } \\
\text { vivos entre el total de } \\
\text { nacidos de mujeres } \\
\text { entre } 15 \text { y } 49 \text { años }\end{array}$ & $-32,26$ & $(28,23)$ & $-0,0377$ & $(0,132)$ & 0,458 & $(0,329)$ \\
\hline $\begin{array}{l}\text { D.proporción de nińos } \\
\text { vivos entre el total de } \\
\text { nacidos de mujeres } \\
\text { entre } 15 \text { y } 49 \text { años, } \\
\text { indígena }\end{array}$ & $-6,360$ & $(10,40)$ & $-0,000742$ & $(0,0471)$ & $-0,0217$ & $(0,0937)$ \\
\hline $\begin{array}{l}\text { D.proporción de niños } \\
\text { vivos entre el total de } \\
\text { nacidos de mujeres en- } \\
\text { tre } 15 \text { y } 49 \text { años, afro }\end{array}$ & $-3,181$ & $(7,326)$ & 0,0509 & $(0,0402)$ & $0,152^{* *}$ & $(0,0687)$ \\
\hline $\mathrm{N}$ & 174 & & 174 & & 174 & \\
\hline r2 & 0,919 & & 0,306 & & 0,848 & \\
\hline $\mathrm{F}$ & 208,5 & & 2,293 & & 33,15 & \\
\hline
\end{tabular}

Notas: Errores estándar robustos en paréntesis. Estimaciones ponderadas por número de hogares por cantón. Número de cantones ajustado por información ausente, dado el carácter aleatorio de la ausencia de información por cantón, descartamos cualquier sesgo de pérdida de información (attrition). 
Un factor que amerita un análisis particular es el relacionado al consumo. Empleamos este factor como una aproximación a las condiciones de bienestar (ingresos) promedio de cada cantón. Como una señal general de estas condiciones este factor está significativamente correlacionado a la participación electoral y muestra una relación inversa, un incremento de una desviación estándar (USD 23,6) en el nivel de consumo promedio en un cantón se relaciona a una disminución de 2,6 \% de la tasa de ausentismo. No obstante, alertamos al lector sobre considerar este efecto (lo mismo en los modelos posteriores) como un efecto causal. Por un lado, el consumo es una medida imprecisa del nivel de ingreso de un hogar, y por lo tanto, la agregación a nivel cantonal únicamente exacerba esa imprecisión.

Por otro lado, típicamente, tanto en encuestas como en los censos, el levantamiento de la información no se realiza bajo ningún criterio de verificación por los costos (ej. tiempo de encuesta) que esto significaría; esto supone confiar en que no existan incentivos negativos a revelar las preferencias del encuestado. Este supuesto es muy fuerte, particularmente en la información censal para este parámetro ${ }^{24}$, los instrumentos estadísticos son más confiables cuando tienen por objeto investigar este comportamiento en específico: encuesta de ingresos y gastos (INEC), encuesta de condiciones de vida (INEC-BID), etc. No conocemos a ciencia cierta el nivel del sesgo y por lo tanto solamente podemos considerar a este parámetro una aproximación imprecisa de las condiciones de vida promedio del cantón.

Finalmente, los resultados relacionados a los indicadores de infraestructura, acceso a servicios públicos y salud validan la idea de que mejores condiciones socio económicas favorecen en general la participación democrática ${ }^{25}$. Se puede observar que, en promedio, un cantón con hogares

24 Verificamos que los promedios observados a nivel cantonal son extremadamente bajos en relación a la información de otros instrumentos estadísticos disponibles y de mayor confiabilidad específica.

25 Tomados individualmente su interpretación está plagada de dificultades. Una aproximación más intuitiva sería la de construir un indicador conjunto de infraestructura (ej. similar al índice de Necesidades Básicas Insatisfechas - NBI, mediante el uso de componentes principales) que resuma el efecto generalizado de estos indicadores. El costo de esta aproximación es el de perder perspectiva sobre el detalle de los factores que explican mejor los resultados electorales. Preferimos dejar explícitos estos indicadores para que el lector saque sus conclusiones y asumiendo el riesgo de la dificultad en la interpretación. Extensiones de este trabajo considerarán este problema. 
que cuentan con mejores condiciones de infraestructura tiende a mayores niveles de participación (aunque solamente uno de estos, el factor de condiciones del piso de la vivienda, es estadísticamente significativo). Dos factores de acceso a servicios son importantes de resaltar. Por un lado, un mayor porcentaje de viviendas con acceso a alcantarillado en un cantón se relacionan con un incremento del nivel de ausentismo electoral; algo similar sucede con la mayor disponibilidad de personal de salud (en general, no únicamente público). Si bien la significancia estadística de ambos factores es baja ( $\mathrm{p}$-value $<0,10)$ ¿cómo interpretar este resultado frente a los demás indicadores de infraestructura? El servicio de alcantarillado está ligado con mayor fuerza a la gestión del municipio y por lo tanto es el alcalde, a través de la gestión municipal, el directo responsable del incremento de su cobertura (algo similar con el acceso a agua potable). Tratándose los resultados de las elecciones a esta dignidad una hipótesis que proponemos es que mejoras generales en el acceso a los servicios atribuibles a la autoridad cantonal supone la satisfacción de una demanda (saciamiento) y por lo tanto disminuye el interés de la participación electoral, es decir, se reducen los incentivos frente a un elemento importante de movilización electoral.

\section{Voto nulo versus voto indefinido}

Otros resultados electorales de interés se relacionan al tipo de decisiones de los electores que escapan al análisis tradicional de las preferencias del votante. Una pregunta latente en todo proceso electoral es cómo interpretar el voto nulo. Existen varias razones por las que este voto se presenta en un proceso. Por un lado, razones menos relevantes desde el punto de vista de las preferencias del votante, son aquellas formales que se derivan de la reglamentación electoral y que, por ejemplo, anulan un voto, porque la marca del voto se sale del casillero o el voto confunde el conteo en la mesa receptora, es decir en no se contabiliza el voto por no seguir adecuadamente la reglamentación.

Más allá de estos casos, existen también los votos nulos que responden a una decisión consciente y que constituyen por lo tanto una expresión 
democrática legítima, a una postura, aun cuando ésta sea de difícil definición ${ }^{26}$. En el Ecuador, "votar nulo" ha formado parte también de una estrategia de diferenciación y posicionamiento político (ver López, 2009), particularmente de organizaciones sociales, frente a posiciones en extremo antagónicas de las alternativas políticas (extrema izquierda versus extrema derecha). Teorizar sobre las motivaciones éticas y políticas de esta respuesta electoral va más allá de los objetivos de esta investigación ${ }^{27}$. Nos remitiremos solamente al criterio de que existe la posibilidad de que esta decisión exprese una forma de "rechazo" o "protesta," bien sea al sistema democrático, bien al proceso electoral específico o bien a las alternativas disponibles, en donde el elector no se sienta representado.

En contraste, se puede analizar la hipótesis alternativa en lo que denominamos arbitrariamente como voto indefinido, y en donde se suman los votos blancos y nulos como una expresión de una decisión electoral distinta, una ausencia de expresión o preferencia determinada, derivada bien del desinterés por el quehacer común, apatía política, confusión o simplemente un nivel bajo de involucramiento y cultura política del electorado. ${ }^{28}$

La Tabla 3 resume los resultados del modelo planteado y podemos observar nuevamente que los indicadores de educación son los más relevantes en ambas alternativas. En promedio, un cantón con mayores tasas de asistencia a educación superior está correlacionado a un mayor porcentaje de votos nulos (un incremento eso sí muy marginal pero consistente, un incremento en la tasa neta de educación superior de $10 \%$ se relaciona a un incremento en el voto nulo menor a 1\%). Resulta interesante observar que

26 Algunos autores se refieren a este tipo de votos como "abstención activa," mientras que se refieren al ausentismo electoral como "abstención pasiva" (Thomson, 2010). En este texto hemos definido abstención y ausentismo como sinónimos por lo que nos referiremos a los demás resultados como "voto nulo" y "voto definido".

27 Varios estudios analizan casos sobre esta perspectiva. El lector interesado puede consultar: Alonso (2010), para el caso Mexicano; López y Cubillo (2009) respecto del Referendum del 2008 en Ecuador.

28 Los votos blancos no contienen una expresión de apoyo o rechazo explícita; dependiendo del sistema electoral y el tipo de elección, estos votos suelen sumarse a la mayoría. El voto nulo también registra que un sufragante se acercó a votar pero su voluntad no favorece ninguna de las alternativas planteadas. En el Ecuador, los votos blancos y nulos no constituyen votos válidos y se excluyen del conteo final. 
la tasa de asistencia a este nivel educativo en la población afro ecuatoriana tiene un efecto distinto, en donde a mayor nivel educativo menor es el porcentaje de votos nulos (aunque nuevamente en un incremento muy marginal). Una hipótesis alternativa que favorece la idea de que estas decisiones tienen un menor nivel de reflexión o demuestran indecisión, se relaciona con mayor fuerza a niveles de educación general y básica, la evidencia que presentamos da cuenta de tres efectos relevantes frente al "voto indefinido," por un lado el de la tasa de asistencia secundaria $(-0,12)$, la tasa de asistencia superior de la población afroecuatoriana $(-0,106)$ y el de la tasa neta de alfabetismo (-0,425), a mayores niveles en estos indicadores menor es el porcentaje de "votos indefinidos" observados en un cantón promedio.

En general, ambos resultados respaldan una misma hipótesis desde perspectivas distintas; un incremento en el nivel educativo de un cantón se relaciona con mayores niveles de participación democrática (menor ausentismo) y menores niveles de indecisión al momento del voto. Al mismo tiempo, el nivel de involucramiento democrático de sus pobladores no es necesariamente unívoco; en otras palabras, también es posible observar que un incremento de la educación superior a nivel cantonal incrementa -marginalmente- el porcentaje de votos nulos presentes. Si la interpretación del voto nulo responde a alguna forma de manifestación de "rechazo," cabe preguntarse por qué se observa este efecto mientras mayor nivel de educación superior tiene un cantón. Los canales mediante los cuales estos resultados se manifiestan son a priori inciertos y varias alternativas son posibles. Si consideramos que el votante que tiene un mayor nivel educativo es en teoría el votante más informado y con mayor capacidad de análisis y que, adicionalmente, por su convivencia en un entorno social (cantón) de mayor el acceso y difusión de información, está más expuesto a un mayor nivel de intercambio de ideas y debate (spill overs), entonces la evidencia sugiere que el voto nulo tiene un origen cognitivo y por lo tanto es necesario ahondar en las motivaciones del fenómeno.

Otros indicadores socio económicos carecen del nivel de influencia respecto de estos resultados electorales. Los indicadores de población y aseguramiento incluidos no son significativos. Sin embargo, podemos 
observar que algunos índices de infraestructura son relevantes y sugieren que mejores condiciones en promedio de las localidades reducen los niveles de rechazo/abstencionismo al proceso electoral; sin embargo, para llegar a conclusiones más determinantes es necesario integrar un criterio de infraestructura global del cantón, no implementado en la presente entrega, por lo tanto no esbozaremos mayores conclusiones de este proceso, los indicadores individuales si bien dan cuenta de una realidad estadística que puede tener asidero en la realidad electoral, no necesariamente facilitan la interpretación de los resultados globales.

\section{Cambios de tendencia política}

En total, de los 212 cantones que conforman nuestro análisis ${ }^{29}$, identificamos un cambio de tendencia ${ }^{30}$ frente al movimiento oficialista en donde éste pierde en 43 cantones y gana en 29; mientras que, si se considera su participación con alianzas de otras organizaciones políticas, éste pierde en 47 y gana en 48 cantones del país (ver Tabla 4). Esto da cuenta de que MPAIS registra mejores resultados al postular con alianzas que al hacerlo solo, captando 31\% del total de alcaldes y prefectos a elegir en el 2014. También se puede observar que la estrategia electoral de las organizaciones políticas nacionales estuvo orientada a la formación de alianzas; sin embargo, resulta interesante observar que las fuerzas políticas más exitosas en las elecciones seccionales a nivel nacional; MPAIS, Avanza y MUPP, son las que acudieron a esta estrategia en menor porcentaje relativo, mientras que en partidos identificados como de oposición las candidaturas exitosas son mayoritariamente en alianza (ver Gráfico 2).

29 Ver sección de Datos para cantones excluidos por el panel.

30 Ver nota de Tabla 4 para la definición de cambio de tendencia. 
Tabla 4.

Resultados electorales del partido de gobierno en las elecciones a Alcalde

\begin{tabular}{c|c|c|c|c}
\hline \multirow{2}{*}{ Elecciones a alcaldes 2009 vs. 2014 } & \multicolumn{2}{|c|}{$\begin{array}{c}\text { Posición frente al } \\
\text { MPAIS }\end{array}$} & \multicolumn{2}{c}{$\begin{array}{c}\text { Posición frente a } \\
\text { (MPAIS + alianzas) }\end{array}$} \\
\cline { 2 - 5 } & N. & Porcentaje & N. & Porcentaje \\
\hline Pierde & 43 & 20,28 & 47 & 22,17 \\
\hline Mantiene tendencia & 140 & 66,04 & 117 & 55,19 \\
\hline Gana & 29 & 13,68 & 48 & 22,64 \\
\hline Total & 212 & 100 & 212 & 100 \\
\hline
\end{tabular}

Fuente: CNE-IDD (2014)

Elaboración: autores

Nota: Cantones que mantienen la tendencia frente al partido de gobierno son todos aquellos en los que el partido de gobierno gana o pierde en ambos períodos. Los cantones seńalados como "Gana" son en donde se adjudicó la dignidad de Alcalde en el 2014, pero no en el 2009; y los señalados como "Pierde," el caso contrario. Empleamos la muestra de análisis.

Gráfico 2.

Composición de las elecciones a alcaldes por organizaciones políticas

\begin{tabular}{|c|c|c|}
\hline PRIAN & $50,0 \quad 50,0$ & PRIAN- 0,9 \\
\hline MPD & 100,0 & MPD 2,7 \\
\hline PSP & $54,5 \quad 45,5$ & PSP- $\quad 5,0$ \\
\hline PSC & 63,6 & PSC $-5,0$ \\
\hline SUMA & 35,3 & SUMA $^{-} \quad 7,7$ \\
\hline CREO & 50,0 & $\mathrm{CREO}^{-10,0}$ \\
\hline MUPP & 34,5 & \begin{tabular}{l|l} 
MUPP- & 13,1
\end{tabular} \\
\hline AVANZA & 22,2 & AVANZA- \\
\hline MPAIS & 37,7 & MPAIS \\
\hline & Composición \% & $\begin{array}{c}0 \quad 10,0 \quad 20,0 \quad 30,0 \quad 40,0 \\
\% \text { del total de alcaldes }\end{array}$ \\
\hline
\end{tabular}

Fuente: CNE-IDD (2014)

Elaboración: autores 
Desde el punto de vista de las condiciones socio-económicas a nivel cantonal, existen varias hipótesis que deben ser indagadas independientemente y que superan los objetivos de este estudio. Una posible explicación de mantener una tendencia electoral es el reconocimiento de la efectividad de la gestión institucional, en este caso municipal y, por lo tanto, un cambio de tendencia puede responder directamente a la inconformidad con la gestión de una administración (castigo). Asimismo, la reelección de autoridades, bien a período seguido o bien autoridades con experiencia previa en la gestión, puede interpretarse como un reconocimiento favorable a la gestión (o trayectoria de servicio público), y en donde el voto se traduce en un mecanismo de retribución del elector.

Por otro lado, cuando se trata de candidatos vinculados a un partido de Gobierno, se agrega un elemento a considerar dentro del mecanismo de decisión y de respuesta del electorado, ya que la percepción de las candidaturas puede asociarse, ya no únicamente a la gestión local sino a la gestión gubernamental nacional. Este mecanismo de asociación funciona en ambas vías, es decir, una percepción favorable de la gestión nacional -potencialmente- favorece las posibilidades de elección a nivel local; y una percepción desfavorable perjudicar la elección local. Otros factores como la percepción sobre los resultados económicos nacionales (ej. inflación, crecimiento económico, etc.) independientemente de si en la realidad son atribuibles o no la gestión pública, pueden formar parte de la percepción del votante y por lo tanto puede influir en la decisión del voto local (Lewis-Beck y Stegmaier, 2000).

Entender esta asociación en el caso ecuatoriano es un reto. Es evidente que la elección mayoritaria de las candidaturas nacionales (presidente y asambleístas) obedece a un nivel de respaldo que no se tradujo en las elecciones seccionales, sobre todo en los principales centros urbanos del país. Entender este divorcio en los resultados electorales en solamente un año de diferencia entre los comicios, es intrigante. Claramente se trata de procesos electorales distintos y como dice la frase popular "los votos no se endosan". El objeto de análisis del votante en 
las elecciones seccionales a nivel cantonal es la figura del alcalde, ${ }^{31}$ y por lo tanto la heterogeneidad de la elección incluye factores propios de los 221 cantones y candidaturas, que no son estrictamente comparables; no obstante, ¿qué pudo cambiar en la tendencia observada entre elecciones seccionales en dos períodos seguidos cuando la fuerza política, al menos de la figura presidencial, se mantiene?

Siguiendo la misma línea propuesta por nuestro modelo, la pregunta que nos planteamos es si ¿el cambio en las condiciones socioeconómicas tiene alguna relación con el cambio de tendencia (favorable/desfavorable) respecto del partido de gobierno? ${ }^{32}$ Si bien en este caso en particular hay

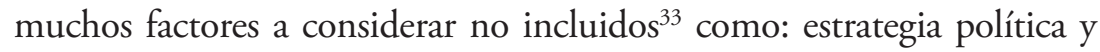
electoral, factores de conflicto social, relación partido de gobierno versus gestión del gobierno, etc.; aportamos al debate en esta sección limitándonos al análisis de las condiciones socioeconómicas buscando aproximarnos informativamente a los factores que influenciaron el voto a nivel local. No está por demás aclarar que los canales mediante los cuales estas condiciones afectan la percepción electoral, y por lo tanto influyen en el cambio de tendencia a nivel cantonal, requieren de mayor estudio y no pueden ser abordados a detalle en este estudio global. Las conclusiones que proponemos del modelo dan cuenta únicamente de identificar (cuantitativamente) si existe o no un efecto y su magnitud.

Los factores del contexto cantonal identificados como influyentes en estos cambios de tendencia son diversos. El único factor que tiene una relación significativa en la desaprobación del partido de gobierno a nivel cantonal es la tasa neta de asistencia secundaria. Un incremento marginal de $1 \%$ en esta tasa de un cantón promedio (tipo) del país

31 Se eligen también concejales urbanos y rurales, lo que influencia también el apoyo, sin embargo la figura que capta y arrastra el apoyo popular más importante es la autoridad local, en este caso el Alcalde.

32 Nótese que nos referimos únicamente a un cambio de tendencia frente al apoyo del partido de gobierno, no al nivel de apoyo total. En otras palabras, no analizamos el apoyo per se al partido sino únicamente la variación que obtuvo entre los dos procesos electorales.

33 Algunos por falta de información específica a nivel cantonal: indicadores productivos, inflacionarios, etc.; otros que siendo factores cualitativos requieren de un análisis particular. 
repercute negativamente en la probabilidad de apoyo al partido de gobierno, alrededor de 2\% (tanto solo como en alianzas). Tomando en cuenta que aún una mayoría de la población ecuatoriana tiene el bachillerato como última instancia de educación formal completa, esta evidencia se aproxima al comportamiento de un votante promedio, y por lo tanto, en promedio, mientras mayor es el nivel educativo respecto de la educación secundaria de la población de un cantón menos probable es el apoyo favorable al partido de gobierno en el cambio de tendencia.

Los factores educativos influyen en el cambio de tendencia favorable/desfavorable condicional al grupo poblacional involucrado. Al 2010, las tasas de asistencia a la educación superior son menores en la población indígena $(7,8 \%)$ y afro ecuatoriana $(9,7 \%)$, frente a las tasas de los grupos poblacionales auto identificados como mestizos $(25,5 \%)$ o blancos $(23,3 \%)^{34}$. En este escenario, los resultados muestran que en la población indígena un incremento marginal en la tasa de asistencia secundaria $(1 \%)$ incrementa la probabilidad de una respuesta desfavorable al partido de gobierno $(0,85 \%$ si va solo, o $0,97 \%$ si va con alianzas). Asimismo, la presencia de población afroecuatoriana en un cantón determina características particulares.

Una respuesta favorable a MPAIS (sin alianzas) está asociada a mayores tasas de asistencia superior en la población afroecuatoriana a nivel cantonal; así un incremento de $1 \%$ en esta variable supone un incremento en la probabilidad de cambio de tendencia favorable de 1,13\%. Este efecto en la población afroecuatoriana se traslada marginalmente al respaldo al partido de gobierno con las alianzas, en donde la educación secundaria gana protagonismo (casi medio punto porcentual). Ambos efectos son levemente significativos (p-value $<0,10$ ). No obstante, el efecto se refuerza si consideramos la probabilidad de una respuesta desfavorable, ésta se reduce significativamente un $2 \%$ frente a un incremento en la tasa de asistencia superior de este grupo poblacional y en casi 3\% frente a un incremento en la tasa de alfabetismo. La evidencia

34 Fuente: CSE(FCT), MCDS-SIISE, INEC. 
que se recoge en estas variables educativas está ligada a la presencia de población indígena y afroecuatoriana en el cantón.

Para el caso indígena, un mayor porcentaje de esta población a nivel cantonal se relaciona a un incremento de la probabilidad de respuesta desfavorable al partido de gobierno en las elecciones de 2014, si este se presentó sin alianzas. Sin embargo, las alianzas demuestran un efecto ambiguo respecto del porcentaje de la población indígena del cantón y los resultados electorales. La probabilidad de una respuesta desfavorable al partido de gobierno se incrementa en 3,15\% con un incremento de $1 \%$ en la población indígena. A su vez, la probabilidad de adjudicarse la candidatura con alianzas se incrementa con la presencia de este mismo grupo poblacional (3,9\%); el efecto neto de las alianzas frente a este grupo poblacional es aún positivo, sin embargo la evidencia presentada da cuenta de la heterogeneidad de la respuesta cantonal. No hay ambigüedad frente a la población afroecuatoriana y el efecto es claramente positivo. Cambios positivos $(1 \%)$ en los porcentajes de población afroecuatoriana a nivel cantonal supone una reducción en la probabilidad de una respuesta desfavorable al partido oficialista de alrededor 4\% (casi 5\% con alianzas).

Respecto de las demás variables de población y aseguramiento podemos observar que respecto de MPAIS con candidaturas propias, ninguna de estas variables tiene poder explicativo en los cantones en donde se observó una respuesta favorable. Al mismo tiempo, una respuesta desfavorable está marginalmente correlacionada a un incremento en la de población en condiciones de indigencia ( $p$-value $<0,05$ ) y a un incremento en el porcentaje de población de la PEA con seguridad social a nivel cantonal.

Por el contrario, considerando al partido de gobierno con sus alianzas, la probabilidad de una respuesta favorable está mayormente correlacionada a las condiciones de pobreza e indigencia aunque el efecto va en direcciones opuestas. Por un lado un incremento en la indigencia se correlaciona a una respuesta favorable $(1,5 \%)$ mientras que incrementos en la tasa de pobreza cantonal, un concepto que abarca la indigencia, explica una reducción de la probabilidad de respuesta favorable $(-1,66 \%)$. 
Las condiciones de pobreza no explican de forma alguna una respuesta desfavorable; sin embargo, en el caso de las alianzas, la medida de extrema pobreza (indigencia) incrementa positiva y significativamente la probabilidad de una respuesta desfavorable. Finalmente, resulta curioso observar que un incremento en los niveles de aseguramiento de la población en edad laboral (PEA) se correlaciona con una mayor probabilidad de respuesta desfavorable al partido de gobierno a nivel cantonal $(3,28 \%$, p-value $<0,01)$. No se incluyen en esta entrega, por limitaciones de información, otros indicadores de empleo y desempleo que pueden ayudar a descifrar estos resultados, en particular, identificar si se trata de una correlación espuria que responde a una dinámica independiente de ambos regresores (ver la sección de análisis de la participación electoral) o de un descontento del votante relacionado a las condiciones de demanda laboral nacional y local que podrían atribuirse, consciente o inconscientemente, a los candidatos del partido de gobierno.

Analizar condiciones de bienestar del cantón requiere de un análisis multidimensional, por lo que medidas de pobreza y extrema pobreza, así como la cobertura del aseguramiento, captan solo parcialmente el fenómeno; similar al caso de las variables de infraestructura, dejamos explícitos estos coeficientes para el análisis del lector interesado y exploraremos en futuros trabajos una combinación que resuma las condiciones de bienestar global en un índice del cantón como un elemento de análisis electoral.

Las variables de infraestructura dan cuenta de una respuesta favorable al partido de gobierno en los cantones en donde estas condiciones mejoraron. La probabilidad de apoyo se incrementa frente a un crecimiento marginal de variables como el porcentaje de viviendas con acceso a red pública de alcantarillado, o eliminación de basuras con carro recolector, esta última variable se refuerza en el caso de la participación del movimiento oficialista con alianzas. Adicionalmente, un efecto similar se observa en relación al porcentaje de hogares con servicio higiénico de uso exclusivo $(1,22 \%$ sin alianzas y $1,44 \%$ con alianzas). Si bien la significancia estadística de los dos primeros factores es baja ( $\mathrm{p}$-value $<0,10)$ resulta informativo 
reconocer que en los cantones que presentan una mejora en aquellos servicios atribuibles a las competencias municipales, la dinámica fue favorable a las candidaturas de MPAIS en el 2014. Ninguno de los factores de infraestructura es significativamente explicativo de la probabilidad de una respuesta desfavorable al movimiento oficialista.

Como se mencionó previamente, estos efectos identificados son efectos promedio a nivel cantonal; empero, esta evidencia sugiere que la respuesta electoral a nivel cantonal en relación a competencias atribuibles a la autoridad local ha sido favorable al partido de gobierno. En otras palabras, no hay evidencia de que cambios positivos en la gestión local expliquen una respuesta desfavorable a MPAIS en las elecciones cantonales. Es importante comprender que la heterogeneidad cantonal es muy rica y que es necesario un análisis profundo cantón por cantón para filtrar estos argumentos. En términos generales la duda que subyace es, si las variables de gestión municipal no explican un cambio de tendencia frente al partido de gobierno (favorable/desfavorable) en la elección de la autoridad local, ¿qué otros factores están involucrados? En la siguiente sección resumimos algunas entrevistas realizadas para tratar de aproximarnos a esta inquietud desde una perspectiva cualitativa. 
Tabla 5.

Cambio de tendencia frente al partido de gobierno e indicadores socio económicos

\begin{tabular}{|c|c|c|c|c|c|c|c|c|c|c|c|c|c|c|c|c|}
\hline \multirow{4}{*}{ 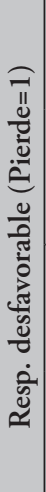 } & \multirow{2}{*}{ 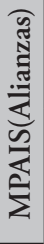 } & య્⿹ & & $\stackrel{\overparen{\infty}}{\stackrel{\check{\Omega}}{=}}$ & $\begin{array}{l}\hat{\tilde{\hat{f}}} \\
\hat{e} \\
\hat{e}\end{array}$ & 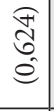 & $\begin{array}{l}\tilde{\hat{\delta}} \\
\tilde{\approx} \\
\approx\end{array}$ & $\begin{array}{l}\text { त̂ } \\
\text { है } \\
\text { है }\end{array}$ & $\begin{array}{l}\text { ङै } \\
\text { ले } \\
\text { é }\end{array}$ & $\begin{array}{l}\stackrel{f}{\infty} \\
\stackrel{\vec{d}}{d}\end{array}$ & $\begin{array}{l}\hat{\hat{E}} \\
\hat{e}\end{array}$ & $\begin{array}{l}\widehat{\widehat{\Xi}} \\
\hat{\varrho}\end{array}$ & $\begin{array}{l}\text { శ్ర } \\
\delta \\
\sqrt{0}\end{array}$ & $\begin{array}{l}\hat{\hat{O}} \\
\infty \\
\hat{e}\end{array}$ & $\stackrel{\nexists}{\stackrel{\Xi}{\Xi}}=$ & \\
\hline & & $\infty$ & & $\begin{array}{l}\stackrel{0}{\widehat{\sigma}} \\
\underset{1}{i}\end{array}$ & $\begin{array}{l}\text { से } \\
\text { ڤे }\end{array}$ & 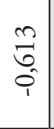 & $\begin{array}{l}\infty \\
\stackrel{\infty}{0} \\
0 \\
0\end{array}$ & 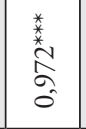 & $\begin{array}{l}\hat{0} \\
\text { ஸे } \\
8 \\
0 \\
0\end{array}$ & $\begin{array}{l}\stackrel{\vec{\lambda}}{n} \\
\text { n. }\end{array}$ & $\begin{array}{l}\text { थิ } \\
0 \\
0\end{array}$ & 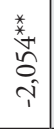 & 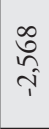 & $\underset{\hat{0}}{N}$ & 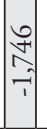 & \\
\hline & \multirow{2}{*}{ 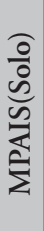 } & య్ర్ల & & $\begin{array}{l}\text { तิ } \\
\stackrel{\S}{\approx}\end{array}$ & $\begin{array}{l}\text { f } \\
\stackrel{+}{t} \\
\text { é }\end{array}$ & $\begin{array}{l}\infty \\
\bar{\sigma} \\
e \\
e\end{array}$ & $\begin{array}{l}\text { त్ } \\
\stackrel{+}{+2} \\
=\end{array}$ & $\begin{array}{l}\text { त̂ } \\
\tilde{\hat{e}} \\
\stackrel{2}{2}\end{array}$ & 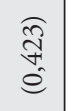 & 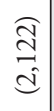 & $\begin{array}{l}\text { ని } \\
\stackrel{\curvearrowright}{\hat{e}} \\
\hat{e}\end{array}$ & 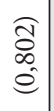 & 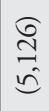 & $\begin{array}{l}\widetilde{a} \\
\hat{\tilde{e}} \\
\hat{e}\end{array}$ & ڤ્ટ & \\
\hline & & $\infty$ & & 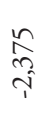 & 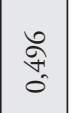 & 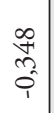 & 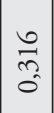 & 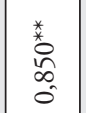 & $\begin{array}{l}n \\
\tilde{n} \\
0\end{array}$ & $\begin{array}{l}\stackrel{n}{\Xi} \\
\hat{n}\end{array}$ & $\underset{0}{\stackrel{m}{f}}$ & 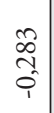 & $\begin{array}{l}\tilde{n} \\
\infty \\
\dot{\forall}\end{array}$ & $\frac{n}{\tilde{0}}$ & 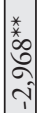 & \\
\hline \multirow{4}{*}{ 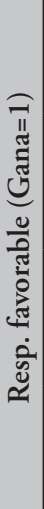 } & \multirow{2}{*}{ 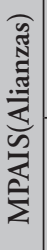 } & $\widetilde{0}$ & & $\begin{array}{l}\text { } \\
\stackrel{0}{2} \\
\stackrel{2}{=}\end{array}$ & $\begin{array}{l}\overrightarrow{\tilde{n}} \\
\hat{n} \\
\stackrel{2}{e}\end{array}$ & $\begin{array}{l}\overparen{\widehat{\hat{\vartheta}}} \\
\hat{\tilde{c}}\end{array}$ & 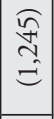 & 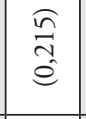 & 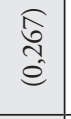 & $\begin{array}{l}\stackrel{\vartheta}{\stackrel{2}{2}} \\
\stackrel{=}{=}\end{array}$ & 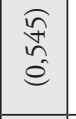 & 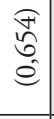 & 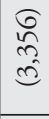 & 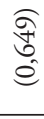 & 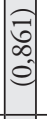 & \\
\hline & & 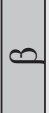 & & $\stackrel{\Omega}{\sigma}$ & $\begin{array}{l}\vec{n} \\
\hat{n} \\
\hat{i}\end{array}$ & $\begin{array}{l}\hat{n} \\
\hat{n} \\
\hat{\rho} \\
1\end{array}$ & 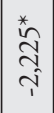 & $\begin{array}{l}\circ \\
\equiv \\
\stackrel{0}{i}\end{array}$ & \begin{tabular}{l}
$\stackrel{*}{*}$ \\
\multirow{0}{*}{}
\end{tabular} & $\begin{array}{c}\tilde{\kappa} \\
\tilde{\tau}\end{array}$ & $\begin{array}{l}\mathbb{F} \\
\tilde{i} \\
\hat{i}\end{array}$ & $\underset{-}{\stackrel{O}{0}}$ & $\begin{array}{l}\stackrel{్}{0} \\
\text { r. }\end{array}$ & $\begin{array}{l}\stackrel{\infty}{+} \\
\stackrel{+}{*}\end{array}$ & I & \\
\hline & \multirow{2}{*}{ 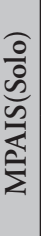 } & య్ర్ల & & $\begin{array}{l}\stackrel{\infty}{\stackrel{2}{2}} \\
\stackrel{2}{=}\end{array}$ & $\begin{array}{l}\frac{\pi}{\tilde{n}} \\
\stackrel{e}{2}\end{array}$ & 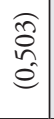 & $\begin{array}{l}\widehat{\approx} \\
\stackrel{0}{0} \\
=\end{array}$ & $\begin{array}{l}\widehat{\hat{े}} \\
\text { స్ } \\
\hat{e}\end{array}$ & 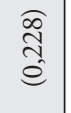 & 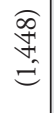 & $\begin{array}{l}\stackrel{2}{2} \\
\stackrel{f}{e} \\
\hat{e}\end{array}$ & $\begin{array}{l}\widehat{\nwarrow} \\
\hat{n} \\
\hat{e}\end{array}$ & $\begin{array}{l}\widehat{\vec{d}} \\
\infty \\
\text { d }\end{array}$ & $\begin{array}{l}\widehat{\vec{\sim}} \\
\hat{\tilde{e}} \\
\hat{e}\end{array}$ & 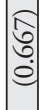 & \\
\hline & & 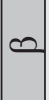 & & 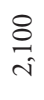 & $\begin{array}{l}\infty \\
\stackrel{n}{a} \\
\hat{p}\end{array}$ & 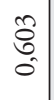 & 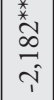 & $\begin{array}{l}\stackrel{\infty}{ \pm} \\
\stackrel{+}{0}\end{array}$ & $\begin{array}{l}\tilde{n} \\
\tilde{\sigma} \\
\tilde{0}\end{array}$ & $\begin{array}{l}\overparen{N} \\
\tilde{n} \\
\hat{1}\end{array}$ & $\begin{array}{l}n \\
\hat{n} \\
\hat{q}\end{array}$ & $\begin{array}{l}\stackrel{*}{\approx} \\
\stackrel{n}{=} \\
=\end{array}$ & $\frac{\stackrel{2}{\Re}}{\stackrel{i}{i}}$ & $\begin{array}{l}\sqrt{0} \\
\text { స్ } \\
0\end{array}$ & $\mid \begin{array}{l}n \\
\infty \\
0 \\
0 \\
1\end{array}$ & \\
\hline & 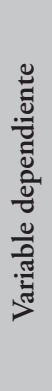 & & 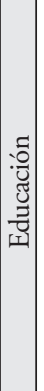 & 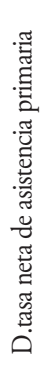 & 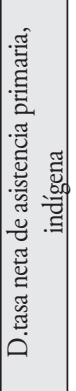 & 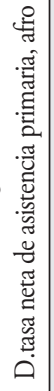 & 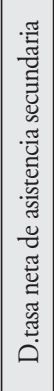 & 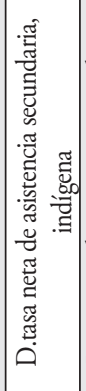 & 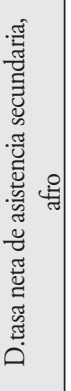 & 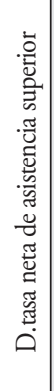 & 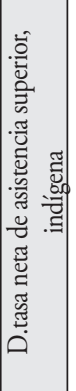 & 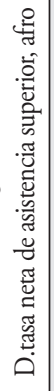 & 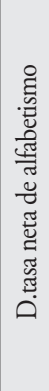 & 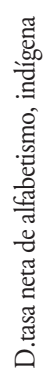 & 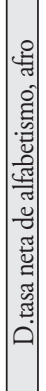 & 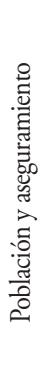 \\
\hline
\end{tabular}




\begin{tabular}{|c|c|c|c|c|c|c|c|c|c|c|c|c|c|c|}
\hline $\begin{array}{l}\hat{\widehat{\sigma}} \\
\stackrel{=}{=}\end{array}$ & $\begin{array}{l}\stackrel{\infty}{\varrho} \\
\stackrel{Ð}{=}\end{array}$ & $\begin{array}{l}2 \\
\hat{2} \\
8 \\
0\end{array}$ & 气ิ & $\begin{array}{l}\hat{\imath} \\
=\hat{\imath} \\
\hat{\imath} \\
\hat{a}\end{array}$ & 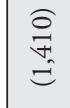 & & 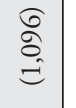 & $\begin{array}{l}\hat{\infty} \\
\hat{\sigma} \\
\hat{e}\end{array}$ & $\begin{array}{l}\frac{\tilde{n}}{\tilde{n}} \\
\hat{e}\end{array}$ & $\begin{array}{l}\widehat{\widetilde{J}} \\
\stackrel{0}{e}\end{array}$ & $\begin{array}{l}\widehat{\widehat{\alpha}} \\
\infty \\
\hat{e}\end{array}$ & $\begin{array}{l}\hat{\mathfrak{n}} \\
\hat{e}\end{array}$ & $\begin{array}{l}\hat{\stackrel{ }{N}} \\
\hat{e}\end{array}$ & \\
\hline 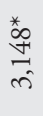 & 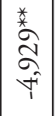 & 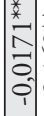 & ד. & ते & $\begin{array}{l}\hat{\&} \\
\hat{ᄋ}\end{array}$ & & $\begin{array}{l}\text { r } \\
\text { ñ } \\
\text { i }\end{array}$ & $\begin{array}{l}\stackrel{n}{0} \\
\hat{o}\end{array}$ & $\begin{array}{l}\stackrel{+}{\infty} \\
\stackrel{n}{0} \\
0\end{array}$ & $\begin{array}{l}\hat{\infty} \\
0 \\
0\end{array}$ & $\begin{array}{l}\text { fôn } \\
\text { î }\end{array}$ & $\begin{array}{l}\stackrel{+}{2} \\
\overrightarrow{0}\end{array}$ & 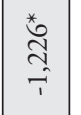 & \\
\hline 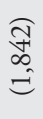 & $\begin{array}{l}\overparen{\Xi} \\
\infty \\
=\end{array}$ & $\begin{array}{l}\infty \\
\hat{1} \\
8 \\
8 \\
0\end{array}$ & \begin{tabular}{l}
\multirow{7}{*}{} \\
0 \\
$=$
\end{tabular} & 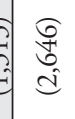 & $\begin{array}{l}\text { } \\
\infty \\
= \\
=\end{array}$ & & $\begin{array}{l}\widehat{\widehat{\beth}} \\
\hat{\widehat{c}} \\
\hat{\varepsilon}\end{array}$ & $\begin{array}{l}\widetilde{n} \\
\infty \\
e \\
e\end{array}$ & $\begin{array}{l}\hat{\widetilde{\pi}} \\
\tilde{\tilde{n}} \\
\hat{e}\end{array}$ & $\begin{array}{l}\text { তิ } \\
\text { ర్} \\
\hat{e}\end{array}$ & $\begin{array}{l}\text { ô } \\
\stackrel{+}{\alpha} \\
\hat{e}\end{array}$ & 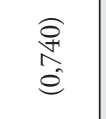 & $\begin{array}{l}\hat{\infty} \\
\stackrel{n}{\hat{e}} \\
\hat{e}\end{array}$ & \\
\hline \begin{tabular}{l}
$\stackrel{*}{*}$ \\
ลิ \\
\multirow{+}{*}{}
\end{tabular} & 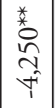 & 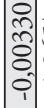 & 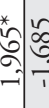 & $\underset{\hat{i}}{\stackrel{+}{*}}$ & \begin{tabular}{l}
$\frac{*}{*}$ \\
\multirow{*}{*}{} \\
$\infty$ \\
ஸे \\
nీ
\end{tabular} & & $\begin{array}{l}m \\
\stackrel{m}{0}\end{array}$ & $\begin{array}{l}\hat{O} \\
\hat{\sigma} \\
0\end{array}$ & 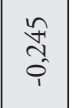 & $\underset{\mathrm{O}}{\mathrm{O}}$ & 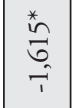 & $\begin{array}{l}\text { Iิ } \\
\text { گิ }\end{array}$ & $\begin{array}{l}\text { ஓे } \\
\text { @े }\end{array}$ & \\
\hline $\begin{array}{l}\widehat{\widehat{\sigma}} \\
\stackrel{\overbrace{}}{=}\end{array}$ & $\begin{array}{l}\widehat{\widehat{N}} \\
\hat{\widetilde{c}} \\
\hat{\sigma}\end{array}$ & 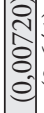 & 矛高 & $\begin{array}{l}\widehat{\widehat{\sigma}} \\
\stackrel{0}{=}\end{array}$ & $\begin{array}{l}\widehat{f} \\
\text { के } \\
\hat{e}\end{array}$ & & $\begin{array}{l}\widehat{\widetilde{n}} \\
\hat{\tilde{n}} \\
\tilde{e}\end{array}$ & $\begin{array}{l}\text { f } \\
\infty \\
e \\
e\end{array}$ & 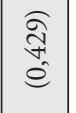 & 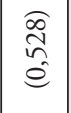 & $\begin{array}{l}\hat{\tilde{\rho}} \\
\hat{e} \\
\hat{e}\end{array}$ & $\begin{array}{l}\widehat{\widehat{\sigma}} \\
\stackrel{0}{0}\end{array}$ & 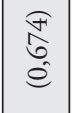 & \\
\hline $\begin{array}{l}\stackrel{*}{*} \\
\stackrel{*}{*} \\
\infty \\
\infty \\
\text { nీ }\end{array}$ & $\begin{array}{l}\stackrel{2}{0} \\
\text { n. } \\
\text { m. }\end{array}$ & 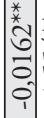 & \begin{tabular}{l}
$*$ \\
\hdashline \\
\hdashline
\end{tabular} & 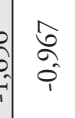 & $\begin{array}{l}\overrightarrow{\widetilde{K}} \\
\hat{\mathbf{Q}}\end{array}$ & & $\begin{array}{l}\text { స్ర } \\
0 \\
0\end{array}$ & $\begin{array}{l}\stackrel{2}{=} \\
\stackrel{7}{\rightarrow}\end{array}$ & $\stackrel{*}{\stackrel{*}{*}}$ & 贲 & $\begin{array}{l}\text { ñ } \\
\hat{n} \\
0 \\
0\end{array}$ & $\begin{array}{l}\tilde{\delta} \\
\text { n. } \\
\text { on }\end{array}$ & $\stackrel{\text { * }}{\stackrel{*}{*} \underset{+}{*}}$ & \\
\hline 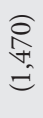 & $\begin{array}{l}\widehat{\curvearrowleft} \\
\hat{\sigma}\end{array}$ & $\begin{array}{l}\text { त్ర } \\
8 \\
8 \\
0\end{array}$ & 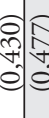 & 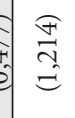 & $\begin{array}{l}\hat{\infty} \\
\hat{\tilde{n}} \\
\hat{e}\end{array}$ & & $\begin{array}{l}\hat{2} \\
\text { है } \\
\tilde{e}\end{array}$ & $\begin{array}{l}\widehat{\approx} \\
\hat{\sigma} \\
\hat{e}\end{array}$ & $\begin{array}{l}\widehat{\hat{\sigma}} \\
\text { n} \\
\hat{e}\end{array}$ & 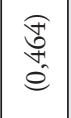 & $\begin{array}{l}\widehat{\overrightarrow{\sqrt{6}}} \\
\hat{e}\end{array}$ & $\begin{array}{l}\widehat{\hat{\kappa}} \\
\hat{n} \\
\tilde{e}\end{array}$ & $\begin{array}{l}\widehat{\approx} \\
\hat{n} \\
\hat{e}\end{array}$ & \\
\hline స్ర & 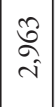 & $\begin{array}{l}0 \\
0 \\
0 \\
0 \\
0 \\
1\end{array}$ & 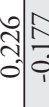 & $\begin{array}{l}\infty \\
\stackrel{0}{\rightarrow} \\
\stackrel{\uparrow}{i}\end{array}$ & $\begin{array}{l}\text { స్ } \\
\text { ठ․ } \\
0\end{array}$ & & \begin{tabular}{l}
\multirow{2}{*}{} \\
0 \\
0 \\
0 \\
1
\end{tabular} & $\stackrel{*}{\stackrel{*}{\rightleftarrows}}$ & 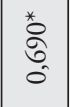 & $\hat{n}$ & 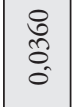 & $\begin{array}{l}\hat{0} \\
\infty \\
i\end{array}$ & $\stackrel{\text { N }}{\stackrel{*}{*}}$ & \\
\hline 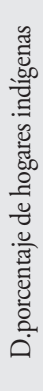 & 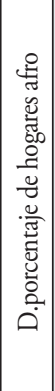 & $\begin{array}{l}0 \\
2 \\
2 \\
\vdots \\
\vdots \\
\vdots \\
0 \\
0 \\
0\end{array}$ & 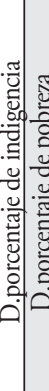 & 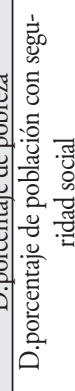 & 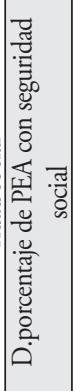 & . & 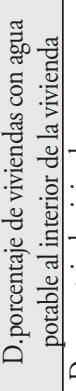 & 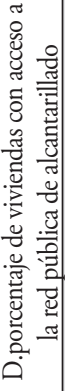 & 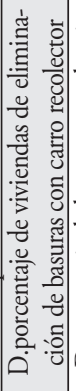 & 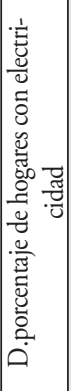 & 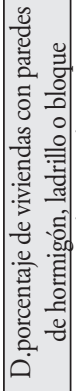 & 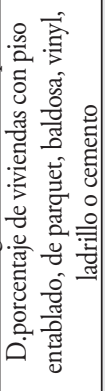 & 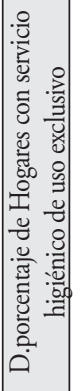 & $\frac{\overrightarrow{3}}{\mathrm{n}}$ \\
\hline
\end{tabular}

DEMOCRACIAS

Vol. 2 • noviembre $2014 \bullet$ pp. 21-75 


\begin{tabular}{|c|c|c|c|c|c|c|c|c|c|c|c|c|c|}
\hline $\begin{array}{l}\text { a } \\
\text { a } \\
\text { a }\end{array}$ & 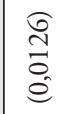 & $\begin{array}{l}\stackrel{\Im}{\hat{F}} \\
\vdots \\
\hat{e}\end{array}$ & & \begin{tabular}{l}
$\hat{\sigma}$ \\
\multirow{2}{\omega}{}
\end{tabular} & & 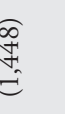 & & $\begin{array}{l}\hat{2} \\
\text { है } \\
\approx\end{array}$ & & & & & 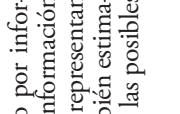 \\
\hline 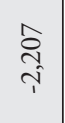 & $\begin{array}{l}\stackrel{*}{*} \\
\text { Dे } \\
0 \\
0 \\
0\end{array}$ & 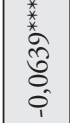 & & 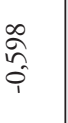 & & 茫 & & ָี & & & & & 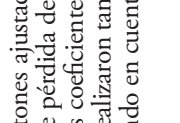 \\
\hline $\begin{array}{l}\hat{8} \\
\stackrel{0}{a}\end{array}$ & $\begin{array}{l}\overparen{\Xi} \\
\stackrel{\Xi}{0} \\
\text { e }\end{array}$ & $\begin{array}{l}\text { त̂ } \\
0 \\
0 \\
\text { e }\end{array}$ & & $\begin{array}{l}\text { तิ } \\
\text { ڤે }\end{array}$ & & 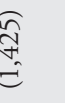 & & 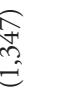 & & & & & 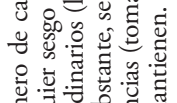 \\
\hline $\begin{array}{l}\hat{b} \\
\text { r. }\end{array}$ & 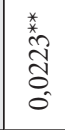 & 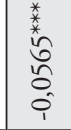 & & $\begin{array}{l}\bar{\Xi} \\
\mathbb{\infty}^{+}\end{array}$ & & \begin{tabular}{c}
$*$ \\
\multirow{2}{*}{} \\
$\infty$ \\
$\infty$ \\
$i$ \\
$i$
\end{tabular} & & $\begin{array}{l}2 \\
\underline{i}\end{array}$ & & 1 & & & 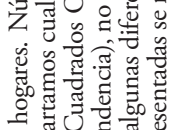 \\
\hline 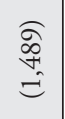 & 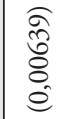 & $\begin{array}{l}\text { तु } \\
\infty \\
0 \\
0 \\
0\end{array}$ & & $\begin{array}{l}\widehat{\partial} \\
\stackrel{\curvearrowright}{\hat{\sigma}}\end{array}$ & & 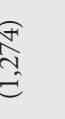 & & 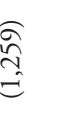 & & & & & 离离 \\
\hline$\underset{0}{\tilde{\sigma}}$ & \begin{tabular}{l}
$\overrightarrow{5}$ \\
\multirow{2}{*}{} \\
0 \\
0 \\
1
\end{tabular} & 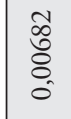 & & $\stackrel{n}{\approx}$ & & 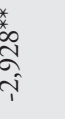 & & $\begin{array}{l}0 \\
\vec{G} \\
i \\
i\end{array}$ & & I & & & 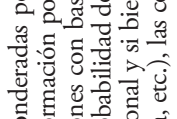 \\
\hline 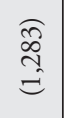 & $\begin{array}{l}\widehat{\tilde{n}} \\
\hat{\tilde{o}} \\
\hat{e}\end{array}$ & 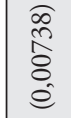 & & 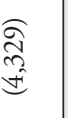 & & $\begin{array}{l}\frac{8}{2} \\
\vdots \\
\vdots\end{array}$ & & $\begin{array}{l}\text { হे } \\
\hat{e}\end{array}$ & & & & & . \\
\hline$\underset{\text { \े }}{\stackrel{0}{0}}$ & $\begin{array}{l}\stackrel{+}{.} \\
\stackrel{8}{8} \\
0\end{array}$ & 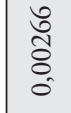 & & $\begin{array}{l}\text { ते } \\
\text { = }\end{array}$ & & ti & & 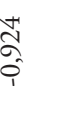 & & 1 & $\hat{\infty}$ & & 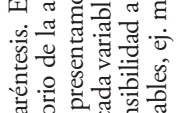 \\
\hline 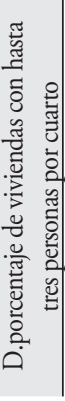 & 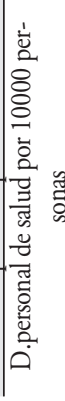 & 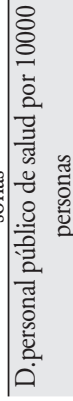 & 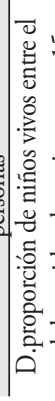 & 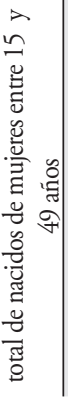 & 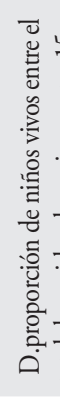 & 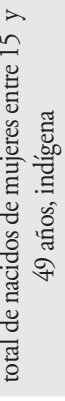 & 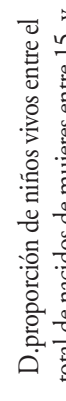 & 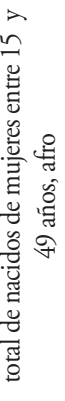 & & 2 & 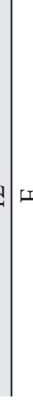 & & 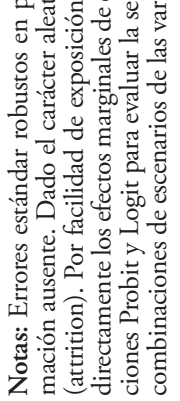 \\
\hline
\end{tabular}


Finalmente, mejoras en las variables de salud demuestran estar correlacionadas inequívocamente con una respuesta desfavorable al partido de gobierno, en sus candidaturas solo y con alianzas. Las competencias de salud no están estrictamente en manos de las autoridades municipales por lo que no cabe pensar que dicho comportamiento a nivel cantonal responde a una mala gestión. Por el contrario, tratándose de competencias del gobierno nacional cabe la posibilidad de que las percepciones se formen en función de la gestión nacional, para posteriormente verse reflejadas en el voto cantonal. Con la información cuantitativa disponible para esta entrega no podemos ahondar en esta relación (o posible interrelación con otros factores).

\section{Discusión de los resultados}

¿Qué no toma en cuenta el modelo? En síntesis, mucho. La aproximación propuesta considera como factores determinantes únicamente los indicadores demográficos y socio económicos disponibles a través de los censos como una aproximación al análisis de la influencia del contexto cantonal en las decisiones del elector. En la medida en que nuestros resultados se entienden desde esa perspectiva, son informativos y contribuyen al debate.

Desde el punto de vista cuantitativo hay otros factores de contexto que influyen directa o indirectamente en los procesos electorales y en la formación de las percepciones del votante, que también varían en el tiempo, y que no están incluidos en esta entrega. Por un lado variables económicas a nivel cantonal: inflación, producción (PIB), desempleo, inversión pública, gasto electoral, etc. forman parte de un esfuerzo estadístico que está en marcha y todavía tiene algunas limitaciones tanto de disponibilidad, recolección, o representatividad. Estos indicadores económicos dan cuenta de un proceso dinámico que es internalizado por el votante; a priori, las diferencias entre el proceso electoral a nivel presidencial y a nivel seccional puede tener aquí asidero. 
El estado de los indicadores económicos y de empleo nacionales, independientemente de si tienen como origen la gestión pública o responden a otras dinámicas económicas, forman parte tanto de la discusión política electoral como del entorno palpable del votante (ej. precio de los alimentos) y por lo tanto, el partido de cualquier gobierno de turno capitaliza/ minimiza sobre su difusión, tratando de afectar las percepciones del votante. Los mismos resultados a nivel nacional no son necesariamente atribuibles a nivel local dado que las competencias de los gobiernos locales tienden a ser más específicas, sin embargo no es posible identificar una medida cierta del nivel de decisión/confusión y por lo tanto atribución de estos resultados nacionales a las elecciones seccionales.

Otros factores que no están explícitos en este documento son de carácter demográfico. Estos también pueden ser complementados aunque a priori, sospechamos de su escasa variabilidad y por lo tanto poco informativa (recordemos que se trata de un modelo de datos de panel, con efectos fijos): composición por edad, género, porcentaje de ruralidad, etc. No hay razón a priori para considerar que estos factores tienen una influencia directa en los resultados y por lo tanto afectar a los regresores del modelo. Las variables educativas, mantienen su nivel y significancia si se incluye la diferenciación de género en el modelo (tasas netas masculinas y femeninas para cada nivel educativo ${ }^{35}$.

Factores coyunturales, como actitudes del candidato hacia temas específicos, comúnmente difundidos a través de los medios de comunicación masiva, mensajes de campaña electoral, etc. no son abordados en este estudio. De igual manera, una extensa lista de factores personales (mencionados en la literatura) o aquellos que influyen en la formación de percepciones del votante en momentos cercanos a la elección, tampoco son parte de este estudio. La contribución de esta información y su análisis es de sustancial importancia para el estudio del comporta-

35 Se probaron varias especificaciones incluyendo los indicadores educativos considerando género, niveles de aseguramiento, otras definiciones educativas (básica, media, superior), y combinaciones. Los modelos expuestos son nuestra especificación preferida y las conclusiones del análisis no se alteran probando otras alternativas. Resultados disponibles bajo pedido. 
miento electoral. Sin embargo, las limitaciones para obtener esta información a nivel cantonal son de tal dimensión que no se conoce estudio alguno en este sentido en el Ecuador.

\section{Otros factores que influyeron en el cambio de tendencia}

Para ampliar nuestro conocimiento sobre otros aspectos de contexto que influyeron en el comportamiento electoral en las elecciones seccionales de 2014 en el Ecuador, realizamos once entrevistas a profundidad que involucraron a: autoridades locales, generadores de opinión y personas involucradas en el tema político, de algunos cantones, grandes y pequeños, en las provincias de Pichincha, Guayas, Azuay, Loja y Zamora. Así resumimos brevemente algunos de los resultados de carácter cualitativo, limitados evidentemente a la selección de los entrevistados ${ }^{36}$, pero que alimenta el debate.

Un primer elemento de coincidencia identificado es que la figura del alcalde, como un líder local, es un factor esencial que determinó la respuesta del votante. Es decir, más que la organización política a la que pertenece, la percepción que existe sobre su liderazgo, trayectoria, personalidad (en unos casos se valora la capacidad de confrontación, en otros de conciliación) y su posición definida (favorable o desfavorable) frente a la figura del Presidente Correa, son aspectos clave que influyeron en la decisión de voto. La importancia de cada uno de estos aspectos varía notablemente de un cantón a otro. Por ejemplo, mientras en Guayaquil se identifica que el discurso de "defender la ciudad frente al gobierno central" es un elemento que tiene cabida entre los votantes; en ciudades como Loja, la coincidencia en el discurso con posturas del Presidente, jugaron favorablemente en la estrategia política; en ambos casos, a pesar del antagonismo con las candidaturas del partido de gobierno.

La diversidad de factores identificados, da cuenta de las particularidades políticas que deben ser consideradas a nivel cantonal. Así, muchos

36 Los entrevistados pertenecieron a varias tendencias políticas auto identificadas, tanto oficialistas como de oposición e independientes. 
de los actores entrevistados identificaron como un error del partido de gobierno el haber realizado una campaña homogénea nacional bajo el lema "la alcaldía de la revolución". En esta línea, el conocimiento que mostró tener el candidato sobre el cantón en cuestión, es identificado como un aspecto primordial para el voto. Sin embargo, en cantones como Quito esta afirmación se pone en duda, pues en el debate de los problemas locales se identifica ampliamente la ventaja del candidato del partido de gobierno (quien postuló a la reelección), no obstante perdió. $\mathrm{Al}$ parecer el votante de las ciudades grandes prioriza el criterio de independencia en la gestión local, y en casos como Quito, la identificación de este criterio, como la condición de "nuevo actor político" del candidato ganador, fue visto favorablemente por los votantes.

Otro factor relevante, identificado en las entrevistas, es el relacionado a la percepción que tiene el votante sobre los conflictos locales y su relación con la gestión gubernamental nacional. Sea por evaluaciones de costo/ beneficio de proyectos implementados, por el establecimiento y aplicación de regulación nacional que interviene directamente en un problema estratégico de la localidad (caso de la pequeña minería en Zamora), efectividad (o falta de ella) de las nuevas instancias de desconcentración regional, entre otros factores, se puede confirmar de alguna forma la influencia y por lo tanto el ruido que interviene en la decisión del voto respecto de la asociación del candidato local con el gobierno central. Las elecciones seccionales de 2014 son particulares en el sentido de que había un gobierno vigente antes del proceso eleccionario; sin embargo, las reformas forman parte de una agenda política de más grande aliento al constituir una presidencia de reelección y por lo tanto no se le puede atribuir esta influencia (positiva o negativa) a esta particularidad.

La generación de empleo, que es un problema que va más allá de las competencias municipales y que al menos es un aspecto de corresponsabilidad del Estado y el sector productivo, aparece como una demanda coincidente en las entrevistas. Todas identifican la importancia que tiene en el votante en contar con fuentes de empleo estables. Posiblemente 
este es uno de los principales desafíos que tiene el gobierno central y local a futuro. Cómo se articulen estos dos niveles de gobierno para su responder a estas demandas y cómo la opinión pública capte la propuesta, podrán ser factores decisivos en el juego político local a futuro.

Finalmente, un factor de coincidencia fuerte identificado en las entrevistas, respecto del cambio de tendencia política en los cantones en donde se levantaron las entrevistas, es la percepción respecto de la conflictividad del liderazgo y conflictos organizativos del partido de gobierno que influyeron en la campańa a nivel local. El "sectarismo," como identifican algunos entrevistados, hacia líderes y organizaciones locales fuera de MPAIS, las luchas internas que dividen en varios grupos a esta misma organización tanto a nivel local como provincial, y cuán evidentes fueron estos conflictos para la opinión pública, para muchos son factores que explican el cambio de tendencia frente al partido de gobierno en varios cantones.

\section{Conclusiones}

La complejidad que involucra el análisis del comportamiento electoral requiere de un análisis extenso y profundo que inevitablemente involucra asumir costos y compromisos respecto de las posibilidades y limitaciones metodológicas. Más todavía en el caso del Ecuador contemporáneo donde son escasos los estudios que existen al respecto y la información disponible es aún limitada. Son innumerables los enfoques para abordar la temática, tanto como los métodos a seguir. Este análisis sobre la base de series de datos estadísticos y entrevistas a profundidad, constituye un primer esfuerzo exploratorio, con el ánimo de promover el debate y la investigación en esta línea.

Los resultados de este análisis dan cuenta de que el nivel educativo de la población es sin duda un determinante -el más consistente- del comportamiento electoral cantonal, y que posiblemente sea un factor igual de robusto para elecciones a otros niveles. Por otra parte, se ob- 
serva que grupos poblacionales como los indígenas o afroecuatorianos, se distinguen del resto de votantes en su comportamiento electoral, más aún si se considera estos grupos poblacionales condicionados por el nivel educativo. Asimismo, se constata que factores que directamente se atribuyen a la gestión local, como el nivel de alcantarillado, influyen en la probabilidad de que un cantón reelija o no a su alcalde.

La influencia de estos factores, junto a otros que todavía requieren de afinación metodológica, se extienden no solamente a la participación electoral y determinación del voto, sino que se relacionan a los cambios de tendencia frente al partido del gobierno titular (incumbent) Presentamos así, evidencia sugerida respecto de la hipótesis del voto retrospectivo (castigo/recompensa), que amerita de mayor análisis, en particular de extensiones que permitan evaluar las motivaciones individuales del voto, y que puedan conciliarse con los resultados de contexto.

La complejidad del análisis del comportamiento electoral se amplifica considerando que a nivel cantonal la diversidad de actores, contextos institucionales, contextos de conflictividad local y la estructura de formación de la opinión pública, son de heterogeneidad abrumadora y por lo tanto no existe uno, sino una combinación de factores que intervienen en el proceso electoral. Por otra parte, analizar los mecanismos y canales de intervención de estos factores, es una tarea pendiente. Presentamos así en esta entrega elementos de debate fundados en un análisis cuantitativo que pretende superar limitaciones previas con el ánimo de contribuir con evidencia consistente que se aproxime a la comprensión del comportamiento del votante en el Ecuador, una tarea que está siempre en proceso. 


\section{Bibliografía}

Andrade, P. (2009). La Era Neoliberal y el Proyecto Republicano, Quito: Corporación Editora Nacional - Universidad Andina Simón Bolívar. Angrist, J. y Pischke. S. (2009). Mostly Harmless Econometrics, Princeton University Press.

Barnes, S. (1997). "Electoral Behavior and Comparative Politics", en

Irving Lichbach, Mark y Zuckerman, Alan S., Comparative Politics, Rationality Culture and Structure, Cambridge University Press.

Burbano de Lara, F. y de la Torre, C. (1989). El populismo en el Ecuador, Quito: ILDIS.

Cameron, C y P. Trivedi. (2010). "Microeconometrics using Stata." Stata Corp LP, Revised Edition.

Campbell, A.; Converse, Philip E.; Miller, Warren E., Stokes, Donald E, "(1960). The American Voter, Jphn Wiley \& Sons, Inc.

Conaghan, C., (1995). "Politicians Against Parties: Discord and Disconnection in Ecuador's Party System", en Building Democratic Institutions: Party Systems in Latin America, Standford: Standford University Press.

Conaghan, C. y De la Torre, C. (2008). The Permanent campaign of Rael Correa: Making Ecuador's Plebiscitary Presidency, Sage Publications.

De la Torre, C. (2009). "Democracia, participación y representación populista en Ecuador", en Tanaka, Martin (ed.), La nueva coyuntura critica en los paises andinos, IDEA y IEP,

De la Torre, C. (2012). "Rafael Correa, un populista del Siglo XXI", en Mantilla, Sebastián y Mejía, Santiago (coord.), Balance de la Revolución Ciudadana, Centro Latinoamericano de Estudios Políticos y Editorial Planeta.

De la Torre, C. (2013). "El tecnopopulismo de Rafael Correa, ¿es compatible el carisma con la tecnocracia?", en Cuvi, Juan; Machado, Decio; Oviedo, Atawallpa; Sierra, Natalia (edit.), El correismo al desnudo, Montecristi Vive, 
Dalton Russell J. y Wattenberg, M., (1993). The Not so Simple Act of Voting", en Ada W. Finifter, ed., Political Science: The State of the Discipline II, Washington D.C. The American Political Science Association.

Downs, A., (1957). An Economic Theory of Political Action in a Democracy“, The Journal of Political Economy, Volume 65, 135-150,

Freidenberg, F. (2000)."Las posiciones ideológicas programáticas en los partidos ecuatorianos." Investigación presentada en el seminario "Partidos Políticos en América Latina, Londres: Instituto de Estudios América Latina.

Freidenberg, F. y Alcántara, M., (2001)."Los dueños del poder: partidos politicos en Ecuador, 1978-2000“, Quito: FLACSO.

Gerber, A., Donald P. Green and Ron Shachar. (2003). "Voting may be habit-forming: evidence from a randomized field experiment." American Journal of Political Science, Vol.47, p.540-550, July.

Leighley, J. and J. N. (1992). "Individual and systemic influences on turnout: who votes? 1984." The Journal of Politics, Vol.54, No.3.

Lewis-Beck, M. y Stegmaier, M. (2000). "Economic Determinants of Electoral Outcomes", Annual Review of Political Science. 3: 183219.

Lipset, Seymour M. y Rokkan, S., (1990).“Cleavage Structures, Party Systems, and Voter Alignments”, New York: Free Press.

Menéndez-Carrión, A., (1986). La Conquista del Voto en el Ecuador, Corporación Editorial Nacional,

Pachano, S. (2004). "El territorio de los partidos. Ecuador, 19792002*, en Partidos Políticos en la Región Andina: entre la crisis y el cambio, IDEA.

Pachano, S. (2006). Ecuador: The Provincialization of Representation“, en Mainwaring, Scott, Bejarano, Ana María y Pizarron Leongómez, Eduardo, The Crisis of Democratic Representation in the Andes, Stanford University Press.

Roberts, K. (próximamente). The Transformation of Party Systems in Latin America. Cambridge University Press. 
Sánchez, F. (2008). ¿Democracia no lograda o Democracia malograda? Un análisis del sistema politico del Ecuador 1979-2002, Quito: FLACSO.

Sartori, G. (1999). Partidos y sistemas de partidos, Madrid: Alianza Editorial.

Weber, M. (1994) Economía y Sociedad: esbozo de la sociología comprensiva V.I. y V.II., Fondo de Cultura Económica, Bogotá.

Weyland, K.. (2002). The politics of Market Reforms in fragile Democracies, Princeton University Press.

Wooldridge, J. (2010). Econometric Analysis of Cross Sections and Panel Data. MIT Press, 2nd. Edition. 
Resultados electorales y el CONTEXTO SOCioeconómico:

UN ANÁLISIS DE LAS ELECCIONES SECCIONALES EN EL ECUADOR 2009-20I 4

\section{Anexos}

\section{Anexo 1.}

Resumen de autoridades seccionales elegidas en el 2014 por tienda política

\begin{tabular}{|c|c|c|c|c|c|c|c|c|c|c|c|c|}
\hline \multirow[t]{2}{*}{ Partido } & \multicolumn{2}{|c|}{ Alcaldes } & \multicolumn{2}{|c|}{$\begin{array}{l}\text { Concej. } \\
\text { Urbanos }\end{array}$} & \multicolumn{2}{|c|}{$\begin{array}{l}\text { Concej. } \\
\text { Rurales }\end{array}$} & \multicolumn{2}{|c|}{ Prefectos } & \multicolumn{2}{|c|}{$\begin{array}{l}\text { Vocales } \\
\text { JPR }\end{array}$} & \multicolumn{2}{|c|}{ Total } \\
\hline & Número & $\%$ & Número & $\%$ & Número & $\%$ & Número & $\%$ & Número & $\%$ & Número & $\%$ \\
\hline Avanza & 28 & 12,7 & 127 & 14,6 & 54 & 12,3 & 0 & 0,0 & 488 & 12,0 & 697 & 12,4 \\
\hline $\begin{array}{c}\text { Avanza } \\
\text { (Alianzas) } \\
\end{array}$ & 8 & 3,6 & 26 & 3,0 & 12 & 2,7 & 1 & 4,3 & 124 & 3,0 & 171 & 3,0 \\
\hline CREO & 11 & 5,0 & 33 & 3,8 & 10 & 2,3 & 0 & 0,0 & 151 & 3,7 & 205 & 3,6 \\
\hline $\begin{array}{c}\text { CREO } \\
\text { (Alianzas) }\end{array}$ & 11 & 5,0 & 48 & 5,5 & 17 & 3,9 & 1 & 4,3 & 200 & 4,9 & 277 & 4,9 \\
\hline MPAIS & 43 & 19,5 & 211 & 24,3 & 125 & 28,5 & 6 & 26,1 & 1035 & 25,4 & 1420 & 25,2 \\
\hline $\begin{array}{c}\text { MPAIS } \\
\text { (Alianzas) }\end{array}$ & 26 & 11,8 & 136 & 15,7 & 62 & 14,2 & 4 & 17,4 & 528 & 12,9 & 756 & 13,4 \\
\hline MPD & 0 & 0,0 & 6 & 0,7 & 5 & 1,1 & 1 & 4,3 & 83 & 2,0 & 95 & 1,7 \\
\hline $\begin{array}{c}\text { MPD } \\
\text { (Alianzas) }\end{array}$ & 6 & 2,7 & 14 & 1,6 & 13 & 3,0 & 2 & 8,7 & 86 & 2,1 & 121 & 2,1 \\
\hline MUPP & 19 & 8,6 & 38 & 4,4 & 41 & 9,4 & 2 & 8,7 & 354 & 8,7 & 454 & 8,1 \\
\hline $\begin{array}{c}\text { MUPP } \\
\text { (Alianzas) }\end{array}$ & 10 & 4,5 & 23 & 2,7 & 21 & 4,8 & 3 & 13,0 & 180 & 4,4 & 237 & 4,2 \\
\hline PRIAN & 1 & 0,5 & 2 & 0,2 & 0 & 0,0 & 0 & 0,0 & 1 & 0,0 & 4 & 0,1 \\
\hline $\begin{array}{c}\text { PRIAN } \\
\text { (Alianzas) }\end{array}$ & 1 & 0,5 & 8 & 0,9 & 2 & 0,5 & 0 & 0,0 & 45 & 1,1 & 56 & 1,0 \\
\hline PSC & 4 & 1,8 & 11 & 1,3 & 3 & 0,7 & 0 & 0,0 & 23 & 0,6 & 41 & 0,7 \\
\hline $\begin{array}{c}\text { PSC } \\
\text { (Alianzas) }\end{array}$ & 7 & 3,2 & 40 & 4,6 & 7 & 1,6 & 1 & 4,3 & 70 & 1,7 & 125 & 2,2 \\
\hline PSP & 6 & 2,7 & 20 & 2,3 & 12 & 2,7 & 1 & 4,3 & 122 & 3,0 & 161 & 2,9 \\
\hline $\begin{array}{c}\text { PSP } \\
\text { (Alianzas) }\end{array}$ & 5 & 2,3 & 28 & 3,2 & 9 & 2,1 & 0 & 0,0 & 120 & 2,9 & 162 & 2,9 \\
\hline SUMA & 11 & 5,0 & 39 & 4,5 & 11 & 2,5 & 2 & 8,7 & 119 & 2,9 & 182 & 3,2 \\
\hline $\begin{array}{c}\text { SUMA } \\
\text { (Alianzas) }\end{array}$ & 6 & 2,7 & 21 & 2,4 & 6 & 1,4 & 1 & 4,3 & 92 & 2,3 & 126 & 2,2 \\
\hline Total & 221 & & 867 & & 438 & & 23 & & 4079 & & 5628 & \\
\hline
\end{tabular}

Fuente: CNE-IDD (2014)

Elaboración: autores

Nota: Los números y porcentajes por partido para el caso de las alianzas corresponden a un doble conteo, es decir, cada alianza fue imputada a todos los partidos involucrados, por lo tanto los porcentajes no suman $100 \%$. 